\title{
Multifractal analysis of gas adsorption isotherms for pore structure characterization of the Bakken Shale
}

\author{
Kouqi Liu ${ }^{\mathrm{a}, *}$, Mehdi Ostadhassan ${ }^{\mathrm{a}}$, Jie Zou ${ }^{\mathrm{b}}$, Thomas Gentzis ${ }^{\mathrm{c}}$, Reza Rezaee ${ }^{\mathrm{b}}$, Bailey Bubach ${ }^{\mathrm{a}}$, \\ Humberto Carvajal-Ortiz ${ }^{\mathrm{c}}$
}

${ }^{a}$ Department of Petrole $\mathrm{mm}$ Engineering, University of North Dakota, Grand Forks, ND 58202

b Department of Petrole $\mu m$ Engineering, Curtin University, Perth, Australia, 6151

${ }^{\mathrm{c}}$ Core Laboratories, Reservoir Geology Group, 6316 Windfern Road, Houston, TX 77040

*Corresponding author, email address: kouqi.liu@ ndus.edu

\begin{abstract}
Understanding pore heterogeneity can enable us to obtain a deeper insight into the flow and transport processes in any porous medium. In this study, multifractal analysis was employed to analyze gas adsorption isotherms $\left(\mathrm{CO}_{2}\right.$ and $\left.\mathrm{N}_{2}\right)$ for pore structure characterization in both a source (Upper-Lower Bakken) and a reservoir rock (Middle Bakken). For this purpose, detected micropores from $\mathrm{CO}_{2}$ adsorption isotherms and meso-macropores from $\mathrm{N}_{2}$ adsorption isotherms were analyzed separately. The results showed that the generalized dimensions derived from $\mathrm{CO}_{2}$ and the $\mathrm{N}_{2}$ adsorption isotherms decrease as $\mathrm{q}$ increases, demonstrating a multifractal behavior followed by $f(\alpha)$ curves of all pores exhibiting a very strong asymmetry shape. Samples from the Middle Bakken demonstrated the smallest average $H$ value and largest average $\alpha_{10-} \alpha_{10+}$ for micropores while samples from the Upper Bakken depicted the highest average $\alpha_{10-}$ $\alpha_{10+}$ for the meso-macropores. This indicated that the Middle Bakken and the Upper Bakken have the largest micropore and meso-macropore heterogeneity, respectively. The impact of rock composition on pore structures showed that organic matter could increase the micropore connectivity and reduce micropore heterogeneity. Also, organic matter will reduce meso-macropore connectivity and increase mesomacropore heterogeneity. We were not able to establish a robust relationship between maturity and pore heterogeneity of the source rock samples from the Bakken.
\end{abstract}

Keywords: Bakken shale; Gas adsorption; Multifractal analysis; Heterogeneity

\section{Introduction}

Oil and gas unconventional shale and conventional hydrocarbon plays contribute a significant amount of petroleum production. Various pore sizes, from nano- to macro- are reported in these reservoirs all around the globe; for example, Second White Speckled Shale [1], Dalong Shale [2], Perth Shale [3], Bakken Shale [4], Barnett Shale [5], and Marcellus Shale [6]. Therefore, understanding the pore structures can result in a deeper insight about the flow and storage capabilities of any porous medium [7-8]. 
During the past decade, a wide range of methods have been applied to characterize these pores including: mercury intrusion porosimetry (MIP) [9], gas adsorption method [10], small angle neutron scattering (SANS) and ultra-small angle neutron scattering (USANS) [11], nuclear magnetic resonance (NMR) [12], direct observation methods such as: field emission scanning electron microscope (FE-SEM) [13-15], atomic force microscopy (AFM) [16-17], microfocus X-ray computed tomography (u-CT) [18-19] and transmission electron microscope (TEM) [20]. In this regard, each method has advantages and disadvantages. For example, FE-SEM can directly detect size and distribution of larger pores but cannot provide any information about micropores because of limitations in tool resolution [4]. MIP determines the largest entrance of mercury into a pore (i.e., pore-throat size) instead of measuring the true pore size [21]. Moreover, a high injection pressure rate will potentially damage the pore structures of the shale with high clay content [22]. The methods that mentioned above can provide us with acceptable information about the porosity and pore size distribution (PSD) of rocks. However, in addition to PSD and porosity as a quantity, the complexity of the pore network is another major parameter that needs to be characterized due to its importance in affecting flow properties and gas storage capacity in different rock samples [23]. Notwithstanding the importance, understanding the complexity of pore structure and pore network in shale formations is still a task that needs further attention.

It is well understood that pore size in shales is not uniformly distributed thus cannot be represented by traditional Euclidean geometry [23-25]. Thus, in order to describe the complexity that exists in pore structures, fractal theory, initially proposed by Mandelbrot [26], has been widely used instead. A fundamental characteristic of a fractal object is that the measured properties are a function of the scale of measurement [27]. So far, several methods have been proposed and used extensively by researchers on methods to define a fractal behavior, such as: box-counting [28-29], fractional Brownian methods [30] and area measurement methods [31-32]. The box-counting method was defined by Russel et al [28] and became one of the most popular methods for gas adsorption isotherms data analysis. This method is defined by applying different boxes of various lengths to cover the whole signal spectrum to be analyzed [28-29]. In addition to box-counting, fractional Brownian is also another method that has been used for fractal analysis and is based on a non-stationary model to describe random phenomenon. This model is a generalized form of Brownian motion where the expected value of intensity differences between two points should be zero. However, the square of the differences should be proportional to the distance between these two points and fit the power law [30]. Another commonly used method for fractal analysis is the area measurement, which uses structuring elements such as triangle, erosion, or dilation of various scales and then computes the area of the signal intensity surface at that corresponding scale. Three algorithms: isarithm method, blanket method, and the triangular prism method are the most popular ones in the area measurement methods to calculate the fractal dimensions [31-33]. 
However, fractal models can only capture a simple fractal behavior that can be described only by one parameter-fractal dimension $\left(D_{0}\right)$. This parameter describes the irregularity within limited size intervals [23, 34-35]. However, in heterogeneous rocks, the pore size distribution (PSD) curve usually fluctuates randomly, jumps off at different pore size intervals [23,34], and the pore size intervals may exhibit various types of self-similarity [36]. All these complexities make it difficult to characterize PSD curves with one single fractal dimension.

Considering the above discussion, multifractals can resolve the issue that is a feature of complex pore structures in heterogeneous rocks. Multifractals can be counted as the extension of fractals or the superposition of monofractal structures [27]. Multifractal analysis, which decomposes self-similar measures into intertwined fractal sets, is characterized by singularity strength of fractal sets and can provide more accurate information about pore structures. The multifractal theory has recently been applied to study pore structures of different rock types such as chalk, carbonate, and shale gas formations [37-39].

Bakken is one of the largest unconventional shale oil plays in the world. The Bakken Formation consists of three members: organic-rich Upper and Lower Bakken and the Middle member, which is composed of mixed carbonates and fine-grained clastics [40]. In previous studies, we analyzed the multifractal behavior of pore structures of the Bakken Formation using SEM images [41]. However, it was described that SEM imaging technique was only able to detect pores that are larger than $9 \mathrm{~nm}$. In order to access and evaluate smaller pores, gas adsorption was later acquired. This made it possible to characterize pores beyond SEM resolution. Accordingly, gas adsorption $\left(\mathrm{CO}_{2}\right.$ and $\left.\mathrm{N}_{2}\right)$ was utilized to analyze pore structure of the Bakken in another study [4]. In our current research approach, we focused on applying multifractal method to analyze the complexity of pore structures in a wide range of pore sizes, ranging from micro- to macro- that exist in the Bakken both in the reservoir (Middle member) and source section (Upper and Lower member) of the formation.

\section{Methods and experiments}

\subsection{Samples}

In order to study the heterogeneity of pore structures and compare pore network complexity that may occur in rocks due to the changes in mineralogy and main constituent components, it was decided to study a few samples from each member of the Bakken Formation and compare the results. With respect to the goals of this research attempt, 4 samples were selected from the Upper Bakken (Samples 1 to 4), 4 samples were selected from the Middle Bakken (Samples 5 to 8) and 3 samples were selected from the Lower Bakken (Sample 9, 10 and 11). The numbers were decided based on sample availability. Thus, a total number of 11 samples were crushed to less than $250 \mu \mathrm{m}$ to be tested by the gas adsorption $\left(\mathrm{CO}_{2}\right.$ and $\left.\mathrm{N}_{2}\right)$ method. 


\subsection{Mineralogy and geochemistry analysis}

A D8 Advance X-ray diffractometer was used to study the mineralogical content of the samples. The scanning measurements were performed at the rate of $2 \% \mathrm{~min}$ in the range of $3-90^{\circ}$. Then, the mineral percentages were estimated by calculating the curve of major peaks [42]. In the next step, Rock-Eval 6® was used to quantify the total organic carbon (TOC) of the samples. This part is specifically important for the samples selected from the source section of the Bakken (Upper and Lower members). To evaluate the TOC of the samples, the trademarked Shale Play method by IFP (Institut Françcais du Pétrol) was applied, and the geochemical properties were derived following the steps suggested by Behar et al [43]. The temperature program for the Shale Play method was set as the following: the initial temperature was $100^{\circ} \mathrm{C}$ which was increased to $200^{\circ} \mathrm{C}$ at $25^{\circ} \mathrm{C} / \mathrm{min}$ and was then kept constant for 3 minutes (for Sh0 calculation). In the next step, temperature was increased to $350^{\circ} \mathrm{C}$ at $25^{\circ} \mathrm{C} / \mathrm{min}$ and held steady for 3 minutes (for Sh1 calculation). Finally, the temperature was raised to $650^{\circ} \mathrm{C}$ at $25^{\circ} \mathrm{C} / \mathrm{min}$. The oxidation cycle reached up to $850^{\circ} \mathrm{C}$. This procedure resulted in measuring all Rock-Eval parameters along with TOC of the samples.

\subsection{Gas adsorption}

All samples were degassed for at least 8 hours at $110^{\circ} \mathrm{C}$ to remove moisture and volatiles that might be present in the samples. Low-pressure nitrogen was measured on a Micromeritics ${ }^{\circledR}$ Tristar II apparatus at $77 \mathrm{~K}$ while carbon dioxide adsorption was measured on a Micromeritics ${ }^{\circledR}$ Tristar II plus apparatus at 273K. Gas adsorption volume was evaluated over the relative equilibrium adsorption pressure $\left(\mathrm{P} / \mathrm{P}_{0}\right)$ range of 0.01-0.99, where $\mathrm{P}$ is the gas vapor pressure in the system and $\mathrm{P}_{0}$ is the saturation pressure of nitrogen [4]. We utilized the density functional theory (DFT) molecular model to quantify pore size distributions from low temperature $\mathrm{N}_{2}$ adsorption isotherms [44] along with non-local density functional theory to obtain and interpret PSD curves by the $\mathrm{CO}_{2}$ adsorption method [45-46]. Based on the fundamental principles of statistical mechanics in explaining the molecular behavior of confined fluids in pore spaces, DFT can be used to describe the adsorption and phase behavior of fluids that are confined in the pore structures. Thus, the density functional theory can better define the thermodynamics behavior and density profiles of such fluids in a molecular level compared to other methods such as Brunauer-Emmett-Teller (BET). Based on the reasons explained earlier, DFT, in comparison with other common techniques, can capture the essential features of both micropore and mesopore filling fluids and their hysteresis response. This can result in a more reliable assessment of pore size distribution curves over a more complete range of values (from micropores to mesopores) [47-48].

\subsection{Multifractal analysis}

The box-counting method, a frequently used method in other studies [28-29, 41], was applied to our data to study the multifractal behavior believed to exist in our data. In order to execute multifractal analysis in a porous media, a set of different boxes with equal length $\varepsilon$ should be used and be laid over the interval in 
the recorded signal to be analyzed. The boxes are labeled by index $i$ where $N(\varepsilon)$ indicates the total number of boxes with size of $\varepsilon$ that is needed to cover the interval understudy (the PSD curve). Accordingly, the section of the $i$ th box of size $\varepsilon$ is denoted as $u_{i}(\varepsilon)$. For gas adsorption, relative pressure $\left(P / P_{0}\right)$ was taken as the length $\varepsilon$ [49-50].

The boxes of length $\varepsilon$ were laid over the heterogeneous pattern of the gas adsorption PSD curve. The probability mass function for the $i$ th box can be calculated using the following equation:

$p_{i}(\varepsilon)=N_{i}(\varepsilon) / N_{T}$

Where, $N_{i}(\varepsilon)$ is the volume of adsorbed nitrogen for the $i$ th box and $N_{T}$ is the total volume of gas that is adsorbed in the pores. Likewise, for each interval of size $\varepsilon, P_{i}(\varepsilon)$ can also be defined by an exponential function of the following form for each box of size $\varepsilon$ as:

$P_{i}(\varepsilon) \sim \varepsilon^{\alpha_{i}}$

where $\alpha_{i}$ is the singularity exponent which represents how singularities of the system approach to infinity as $\varepsilon$ gets closer to 0 [51-52]. For multifractally distributed properties of intervals of size $\varepsilon, N(\varepsilon)$ increases when $\varepsilon$ decreases following a power law function of the form:

$$
N_{\alpha}(\varepsilon) \sim \varepsilon^{-f(\alpha)}
$$

where $N_{\alpha}(\varepsilon)$ is the number of boxes for which probability mass function of the $i$ th box, $P_{i}(\varepsilon)$, has singularity strength between $\alpha$ and $\alpha+d \alpha$. Then, $f(\alpha)$ represents the spectrum of the fractal dimensions that characterizes the abundance in the set with $\alpha$ singularity. Subsequently, $\alpha(q)$ and $f(\alpha)$ can be calculated based on the equations that are proposed by Chhabra and Jensen [53]:

$$
\begin{aligned}
& \alpha(q) \propto\left[\sum_{i=1}^{N(\varepsilon)}\left(u_{i}(q, \varepsilon) \times \ln p_{i}(\varepsilon)\right)\right] / \ln (\varepsilon) \\
& f(\alpha) \propto\left[\sum_{i=1}^{N(\varepsilon)}\left(u_{i}(q, \varepsilon) \times \ln u_{i}(q, \varepsilon)\right)\right] / \ln (\varepsilon)
\end{aligned}
$$

where

$$
u_{i}(q, \varepsilon)=\frac{p_{i}(\varepsilon)^{q}}{\sum_{i=1}^{N(\varepsilon)} p_{i}(\varepsilon)^{q}}
$$


Here, $q$ is the exponent expressing the fractal properties in different scales of the object. In this study, $\alpha$ and $f(\alpha)$ were calculated through a linear regression using Eq. 4 and Eq. 5 with $q$ varying from -10 to 10 for successive unit steps. For multifractal applications, a probability distribution function is defined as:

$u(q, \varepsilon)=\sum_{i=1}^{N(\varepsilon)} P_{i}(\varepsilon)^{q} \sim \varepsilon^{\tau(q)}$

Where $\tau_{q}$ is the mass scaling function of order $q$ which can be defined as:

$\tau(q)=\lim _{\varepsilon \rightarrow 0}\left[\ln \sum_{i} P_{i}(\varepsilon)^{q} / \ln (1 / \varepsilon)\right]$

thus, the generalized dimension $\left(D_{q}\right)$ which is related to $q$ can be expressed as [52]:

$D_{q}=\tau(q) /(q-1)$

While for $q=1, D_{q}$ will become:

$D_{1}=\lim _{\varepsilon \rightarrow 0}\left(\sum_{i=1}^{N(\varepsilon)} p_{i}(\varepsilon) \ln p_{i}(\varepsilon) / \ln (\varepsilon)\right.$

\section{Results and discussion}

3.1. Multifractal analysis of $\mathrm{CO}_{2}$ adsorption

The $\log -\log$ plot of the partition function $u(q, \varepsilon)$ versus the length scale $\varepsilon$ for the interval of $q=-10$ to $q=10$ at successive intervals of $q=1$ was created and is shown for the representative samples of each member of the Bakken Formation in Fig. 1. The plots demonstrated that a linear relationship exists between $\log u(q, \varepsilon)$ and $\log \varepsilon$ of these representative samples from the Upper, Middle and Lower Bakken. This shows the existence of a multifractal behavior for pore size distributions (PSD) curves in our samples. The results show a clear distinction between the partition function of $q>0$ and $q<0$ with negative and positive slopes, respectively. In addition, the regression lines are found very close to one another, indicating that most of the measured data can be concentrated in a small size domain of the study scale [49]. 


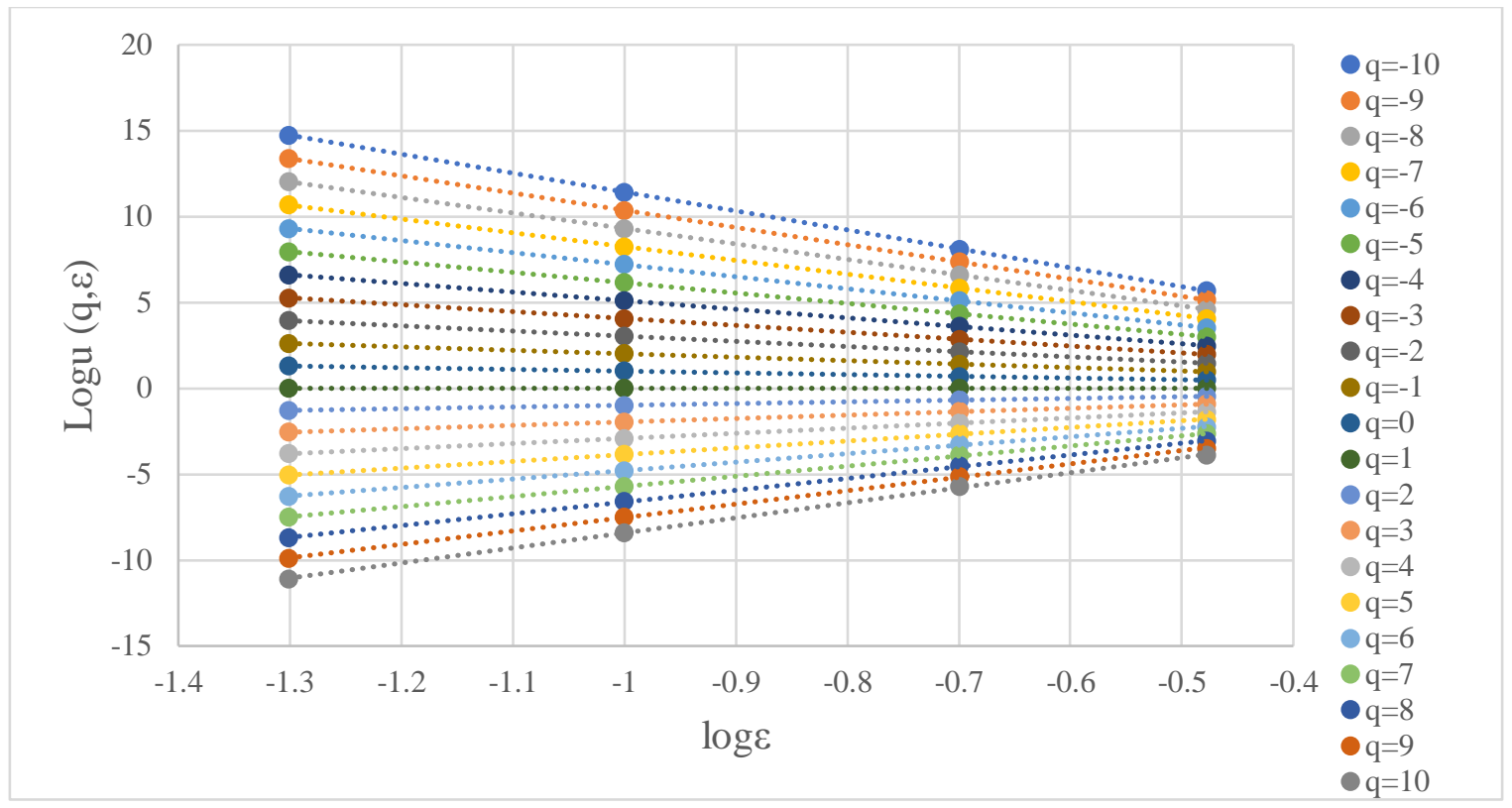

(a) Sample 1(Upper Bakken)

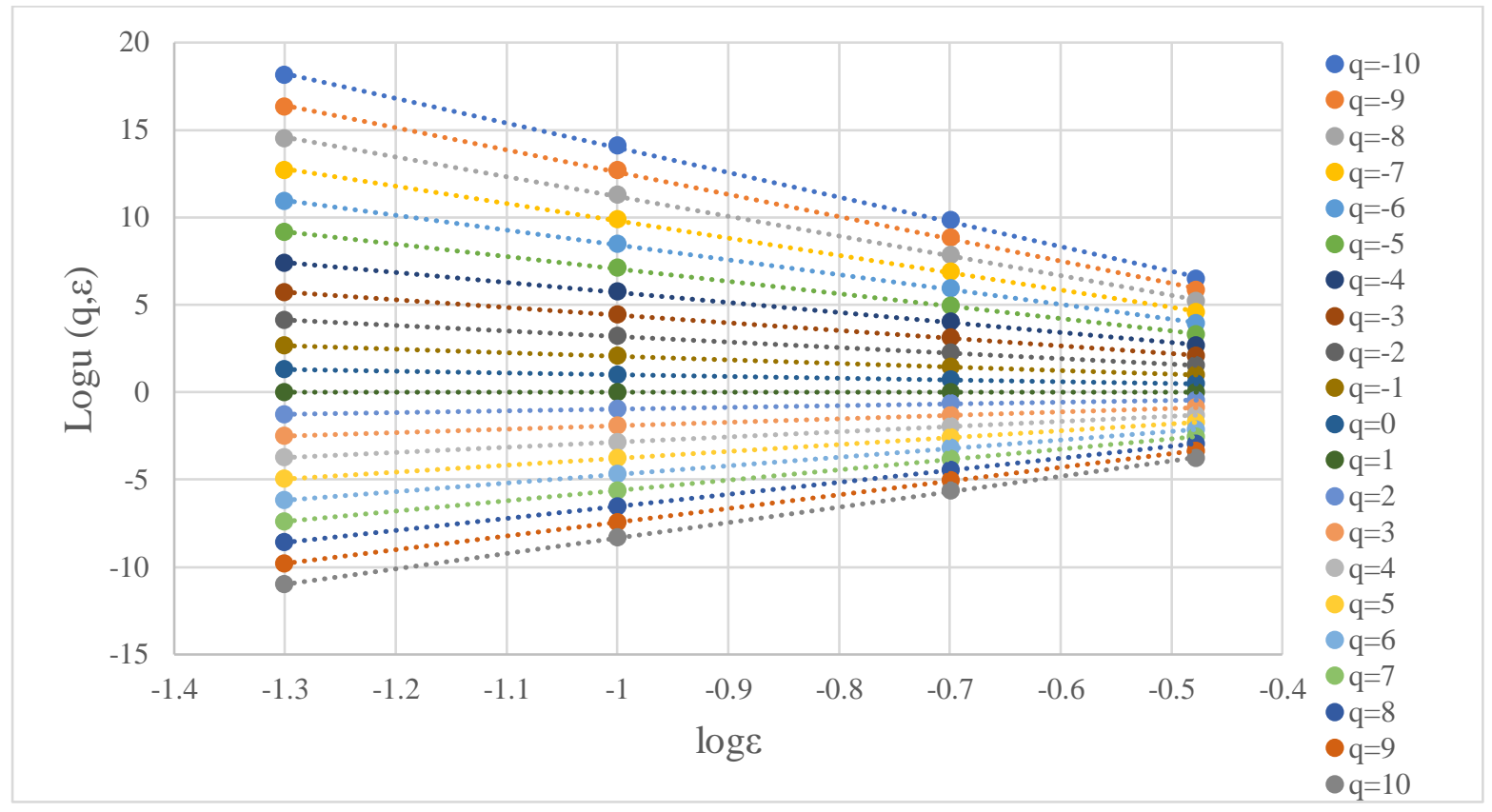

(b) Sample 5 (Middle Bakken) 


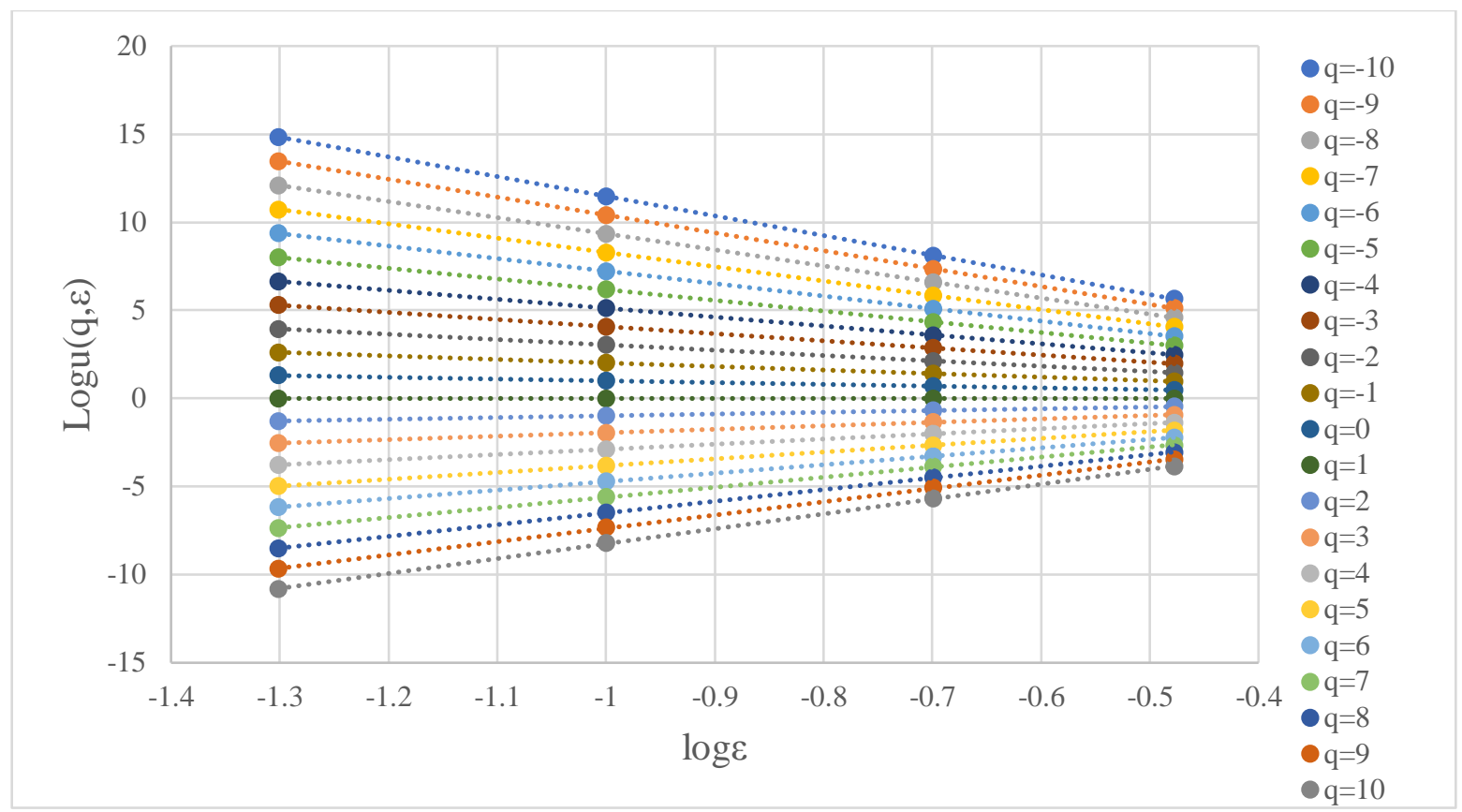

(c) Sample 9 (Lower Bakken)

Fig. 1. Log-log plots of the partition function versus box scale of samples from different members of the Bakken from $\mathrm{CO}_{2}$ adsorption isotherms.

Combining Eq. 9 and Eq. 10, the generalized dimensions $D_{q}$ from $\mathrm{CO}_{2}$ adsorption of all studied samples were calculated and are presented in Fig. 2. The curves for all samples followed a monotonic decrease as $q$ increased. The data, summarized in Table 1, represents $D_{0}>D_{1}>D_{2}$, and demonstrates that the distributions of pore size fit a multifractal behavior, in agreement with the results derived from Fig. 1[49].

$D_{0}$ represents singularity of non-empty boxes containing some value of porosity under successive finer partitions, which is independent of the probability of the porosity in that box. From Table 1 it can be found that the capacity $D_{0}$ of all samples is the same and equal to $1 . D_{l}$, the entropy information can characterize the concentration degree of the pore size distribution along the pore size intervals. The indicator $D_{0}-D_{l}$ can be used to describe the degree of uniform distributions across a specific range of pore sizes [23, 54]. The results in Table 1 illustrate that the Middle Bakken has higher $D_{0}-D_{l}$ values ( 0.0087 on average) compared to the $D_{0}-D_{l}$ values calculated from the Upper ( 0.0035 on average) and Lower Bakken ( 0.0060 on average). This verifies that the Middle Bakken has the most clustered style of pore size distribution. Thus, we can conclude that the pore size distribution (PSD) in the Upper and Lower Bakken is more homogeneous. Fig. 3 shows the pore size distributions of the samples based on $\mathrm{CO}_{2}$ adsorption. While comparing the pore size distributions of the Eagle Ford Formation, which is a calcareous shale that produces both oil and gas in Texas with our samples from the Bakken Formation, smaller pore volumes with sizes less than $1 \mathrm{~nm}$ were 
detected [55]. In this regard, pore size from the Upper Bakken and the Lower Bakken varies from $0.4 \mathrm{~nm}$ to $1.8 \mathrm{~nm}$ while the pore size from the Middle Bakken is measured between $1.2 \mathrm{~nm}$ to $1.8 \mathrm{~nm}$. Fig. 3 depicts that the Middle Bakken with the narrowest pore size range has the most grouped pore size distribution, confirming that $D_{0}-D_{l}$ can be a good indicator to describe the concentration degree of pore size distributions.

$D_{2}$ is defined as the correlation dimension, which accounts for the behavior of the second sampling moments. Table 1 shows that samples from the Middle Bakken have smaller $D_{2}$ values than the Upper and Lower Bakken. $H$, which is $\left(D_{2}+1\right) / 2$, and is known as the Hurst exponent [56]. $H$ can vary from 0.5 to 1 and indicates the degree of the positive autocorrelation. A smaller $(1-H)$ value is corresponding to a stronger autocorrelation in size-dependent distribution of any property, porosity in this case. The Middle Bakken has the largest value of (1- $H$ ) with the average of 0.0076 compared to the samples from the Upper Bakken (0.0038 on average) and Lower Bakken (0.0064 on average). This is a representative of the lowest autocorrelation in the size dependent distribution of porosity, which agrees with pore size distributions that were found in Fig. 3. $H$ can also be used to specify the pore connectivity across the pore size network of various sizes, which can affect the permeability or flow through the sample [34]. A smaller $H$ value represents poor pore connectivity, which was calculated to be the smallest for the Middle Bakken.

The difference between $D_{10-}-D_{10+}$ of the $D_{q}$ spectrum is that it can characterize the heterogeneity of the porosity distribution over the entire pore size range (0-2 nm that was measured by $\mathrm{CO}_{2}$ adsorption). Table 2 shows that samples from the Middle Bakken have the highest $D_{10-}-D_{10+}$ value with an average of 0.2100 compared to the samples from the Upper Bakken (0.062 in average) and Lower Bakken (0.0933 in average). Overall, considering the micropores that exist in the samples, the Middle Bakken has the highest level of heterogeneity in porosity distribution while samples from the Upper Bakken have the least degree of heterogeneity in the distribution of pore sizes.
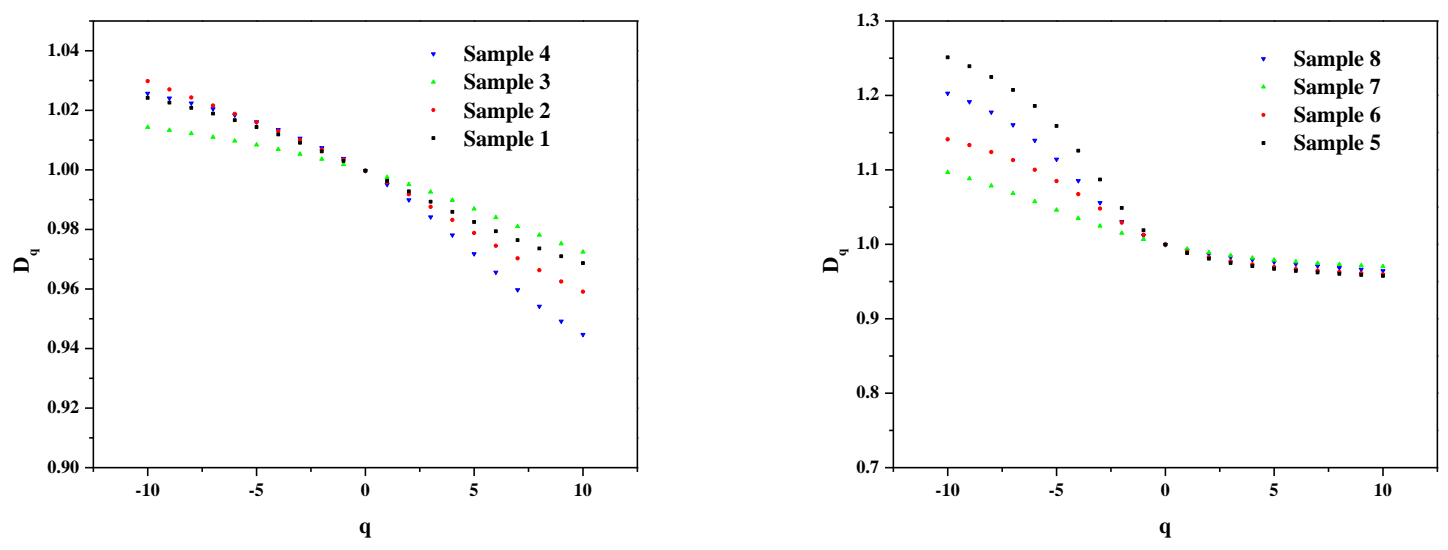
(a) Upper Bakken

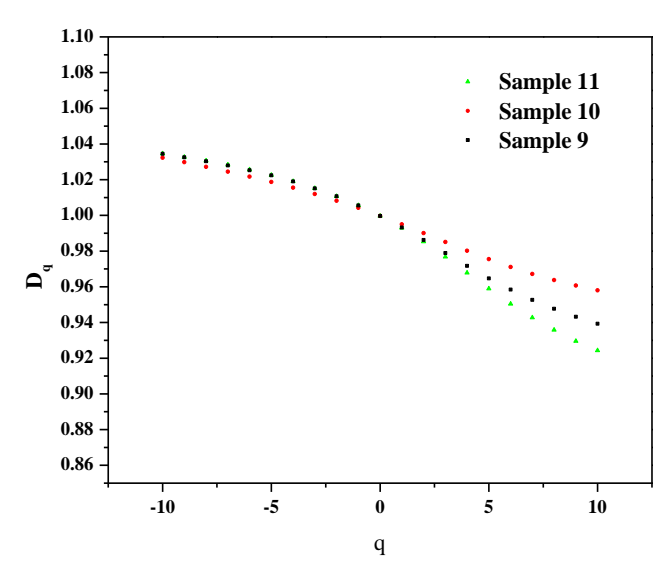

(c) Lower Bakken (b) Middle Bakken

Fig. 2. The relationships between $D_{q}$ and $q$ of the samples from $\mathrm{CO}_{2}$ adsorption isotherms.

Table 1 Characteristics of the generalized dimension from all the samples from $\mathrm{CO}_{2}$ adsorption

\begin{tabular}{ccccccccc}
\hline & $D_{10+}$ & $D_{10-}$ & $D_{0}$ & $D_{1}$ & $D_{2}$ & $D_{0-} D_{1}$ & $H$ & $D_{10-}-D_{10+}$ \\
\hline Sample 1 & 0.9687 & 1.0242 & 0.9997 & 0.9963 & 0.9928 & 0.0034 & 0.9964 & 0.0555 \\
\hline Sample 2 & 0.9591 & 1.0298 & 0.9997 & 0.9959 & 0.9918 & 0.0038 & 0.9959 & 0.0707 \\
\hline Sample 3 & 0.9724 & 1.0143 & 0.9997 & 0.9975 & 0.9951 & 0.0022 & 0.9976 & 0.0419 \\
\hline Sample 4 & 0.9447 & 1.0257 & 0.9997 & 0.9951 & 0.9899 & 0.0046 & 0.9950 & 0.0810 \\
\hline Sample 5 & 0.9576 & 1.2511 & 0.9997 & 0.9882 & 0.9806 & 0.0115 & 0.9903 & 0.2935 \\
\hline Sample 6 & 0.9599 & 1.1410 & 0.9997 & 0.9900 & 0.9827 & 0.0097 & 0.9914 & 0.1811 \\
\hline Sample 7 & 0.9701 & 1.0968 & 0.9997 & 0.9938 & 0.9890 & 0.0059 & 0.9945 & 0.1267 \\
\hline Sample 8 & 0.9644 & 1.2029 & 0.9997 & 0.9920 & 0.9867 & 0.0077 & 0.9934 & 0.2385 \\
\hline Sample 9 & 0.9393 & 1.0345 & 0.9997 & 0.9932 & 0.9862 & 0.0065 & 0.9931 & 0.0952 \\
\hline Sample 10 & 0.9580 & 1.0323 & 0.9997 & 0.9950 & 0.9901 & 0.0047 & 0.9951 & 0.0743 \\
\hline Sample 11 & 0.9243 & 1.0346 & 0.9997 & 0.9930 & 0.9853 & 0.0067 & 0.9927 & 0.1103 \\
\hline
\end{tabular}




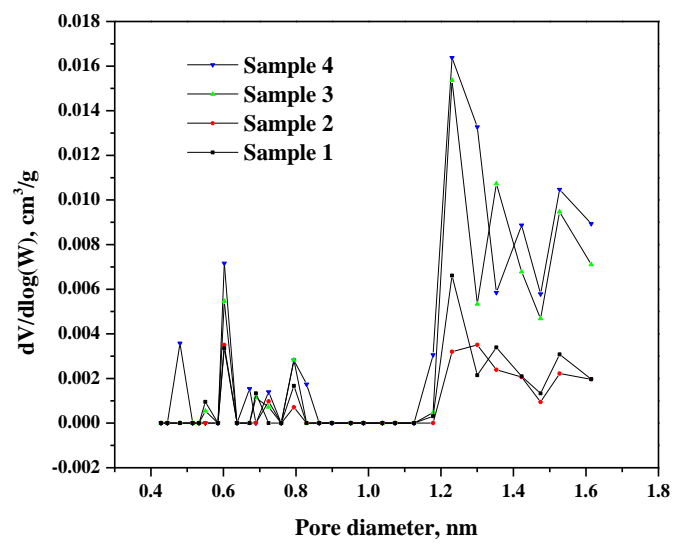

(a) Upper Bakken

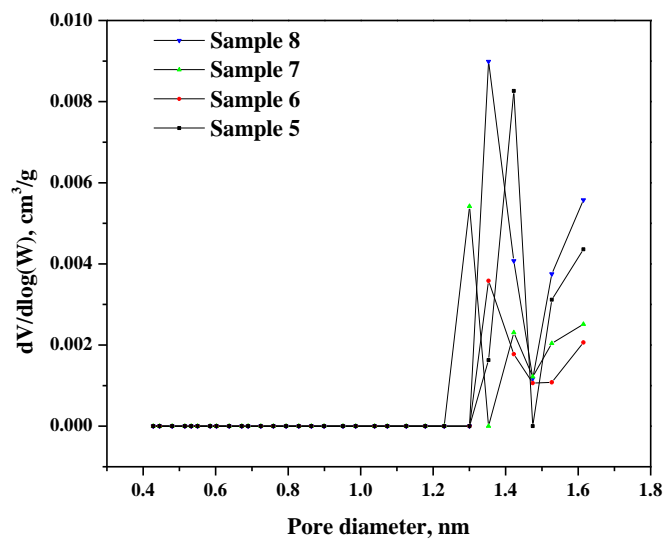

(b) Middle Bakken

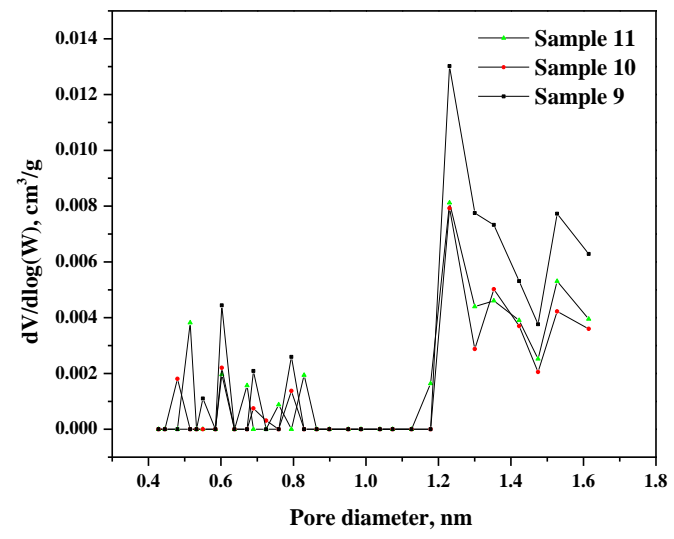

(c) Lower Bakken

Fig. 3. Pore size distributions of the sample from the $\mathrm{CO}_{2}$ adsorption.

The $f(\alpha)$ curves versus $\alpha$ for all samples are shown in Fig. 4, which demonstrates a strong asymmetric (around $\alpha$ equal to 1) convex parabolic shape. For the samples from the Upper and Lower Bakken, the portion of the curve with the negative slope is wider and extends longer than the portion of the curve with the positive slope. In other words, the absolute value of the curve tangent on the left side of the symmetry line (around $\alpha$ equal to 1 ) is larger than the right portion of the curve. In contrast, for the samples from the Middle Bakken, the portion of the curve with the positive slope is wider compared with the left portion with the negative slope. All of these behaviors explain that pore size distributions (PSD) of all samples exhibit a multifractal behavior. The results in Table 2 show that the samples from the Middle Bakken have a higher $\alpha_{0}$ value (1.0102 on average) than the samples from the Upper (1.0031 on average) and Lower Bakken 
(1.0054 on average), meaning that the Middle Bakken has a higher degree of pore size distribution concentrations over a specific range of pore size. This conclusion verifies the results from Fig. 3 and the Hurst exponent $(H)$.

The value of $\alpha_{10_{-}-} \alpha_{10+}$ is used to describe the degree of heterogeneity of the pore size distribution. Larger $\alpha_{10-}-\alpha_{10+}$ can be translated to a more heterogeneous pore size distribution within the sample. The calculation revealed that the samples from the Middle Bakken have a larger $\alpha_{10_{-}}-\alpha_{10+}$ value with 0.3240 on average than the samples retrieved from the Upper Bakken (0.1089 on average) and Lower Bakken (0.1497 on average). This indicates that the pore size distribution in the Middle Bakken has a more internal difference from the multifractal analysis perspective [44]. Thus, pore size distribution in the Middle Bakken is more heterogeneous than in the Upper and Lower Bakken. The left side of the $f(\alpha)$ curve with respect to the symmetry line represents areas with higher probability density of the pore volume distribution while the right portion corresponds to areas with lower probability density [54]. We used a parameter known as $R_{d}$, which is defined as $\left(\left(\alpha_{0^{-}} \alpha_{10+}\right)-\left(\alpha_{10^{-}} \alpha_{0}\right)\right)$, to show the departure degree of the $f(\alpha)$ spectrum from the center or the symmetry line. The results in Table 2 display that samples from the Middle Bakken all have negative $R_{d}$ values, indicating that pore size distributions in these samples are dominated mostly by areas with higher probability (concentrated areas). In contrast, the samples from the Upper and Lower Bakken Formation all have positive $R_{d}$ values, inferring that pore size distributions of these samples are dominated by areas with lower probability (sparse areas).

Table 2 Characteristics of the multifractal singularity spectra from $\mathrm{CO}_{2}$ adsorption

\begin{tabular}{cccccccc}
\hline & $\alpha_{0}$ & $\alpha_{10+}$ & $\alpha_{10-}$ & $\alpha_{0^{-}} \alpha_{10+}$ & $\alpha_{10-}-\alpha_{0}$ & $\alpha_{10-}-\alpha_{10+}$ & $R_{d}$ \\
\hline Sample 1 & 1.0031 & 0.9483 & 1.0412 & 0.0548 & 0.0381 & 0.0929 & 0.0167 \\
\hline Sample 2 & 1.0035 & 0.9295 & 1.0597 & 0.0740 & 0.0562 & 0.1302 & 0.0178 \\
\hline Sample 3 & 1.0018 & 0.9484 & 1.0252 & 0.0534 & 0.0234 & 0.0768 & 0.0300 \\
\hline Sample 4 & 1.0041 & 0.9063 & 1.0419 & 0.0978 & 0.0378 & 0.1356 & 0.0600 \\
\hline Sample 5 & 1.0143 & 0.9475 & 1.3715 & 0.0668 & 0.3572 & 0.4240 & -0.2904 \\
\hline Sample 6 & 1.0110 & 0.9486 & 1.2207 & 0.0624 & 0.2097 & 0.2721 & -0.1473 \\
\hline Sample 7 & 1.0062 & 0.9589 & 1.1869 & 0.0473 & 0.1807 & 0.2280 & -0.1334 \\
\hline Sample 8 & 1.0092 & 0.9469 & 1.3186 & 0.0623 & 0.3094 & 0.3717 & -0.2471 \\
\hline Sample 9 & 1.0059 & 0.9061 & 1.0554 & 0.0998 & 0.0495 & 0.1493 & 0.0503 \\
\hline Sample 10 & 1.0043 & 0.9354 & 1.0598 & 0.0689 & 0.0555 & 0.1244 & 0.0134 \\
\hline Sample 11 & 1.0060 & 0.8789 & 1.0542 & 0.1271 & 0.0482 & 0.1753 & 0.0789 \\
\hline
\end{tabular}




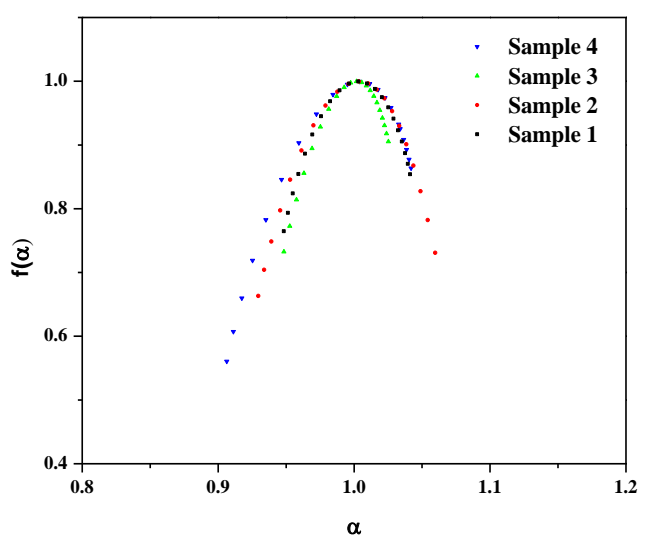

(a) Upper Bakken

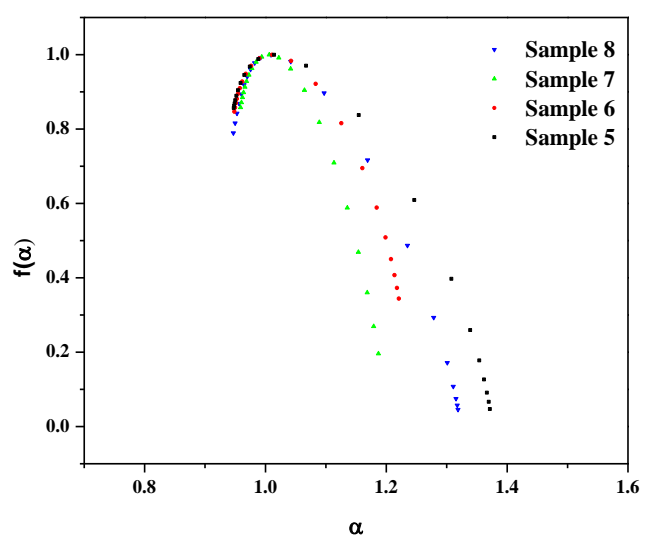

(b) Middle Bakken

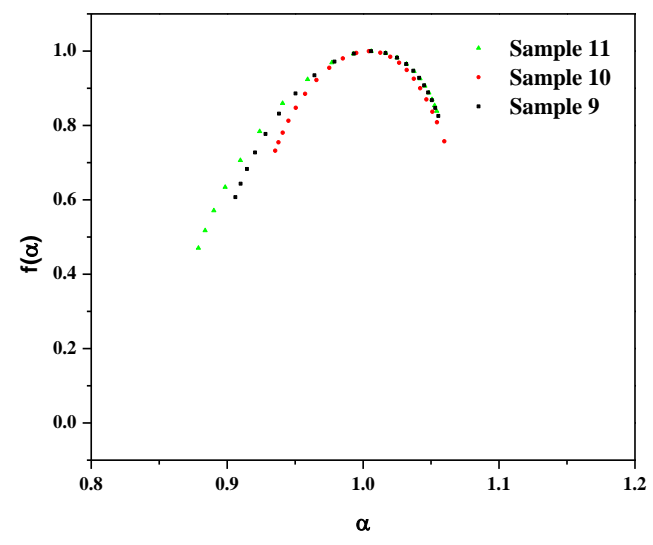

(c) Lower Bakken

Fig. 4. Multifractal singularity spectra $f(\alpha)$ for the Bakken samples from $\mathrm{CO}_{2}$ adsorption isotherms.

\subsection{Multifractal analysis of $\mathrm{N}_{2}$ adsorption}

The $\mathrm{N}_{2}$ adsorption method can access the pores in the range of meso- to macro-scale which $\mathrm{CO}_{2}$ adsorption is incapable of detecting since it measures only the distribution of micropores. In this part, we will analyze the multifractal behavior of the pore size distribution by nitrogen adsorption. For this purpose, the $\log$ - $\log$ plots of the partition function $u(q, \varepsilon)$ versus the length scale $\varepsilon$ between $q=-10$ to $q=10$ at successive intervals of $q=1$ were made based on nitrogen adsorption isotherms and are displayed for representative samples of each member of the Bakken in Fig. 5. The curves show that pore size distributions from the nitrogen adsorption exhibit a multifractal behavior. Similar to the curves in Fig. 1, the partition function has a notable difference between $q>0$ and $q<0$ with negative and positive slopes, respectively. Also, the regression lines 
are very close to each other, indicating that the majority of pore size distributions are concentrated in a small size domain of the study scale that was measured by nitrogen adsorption isotherms.

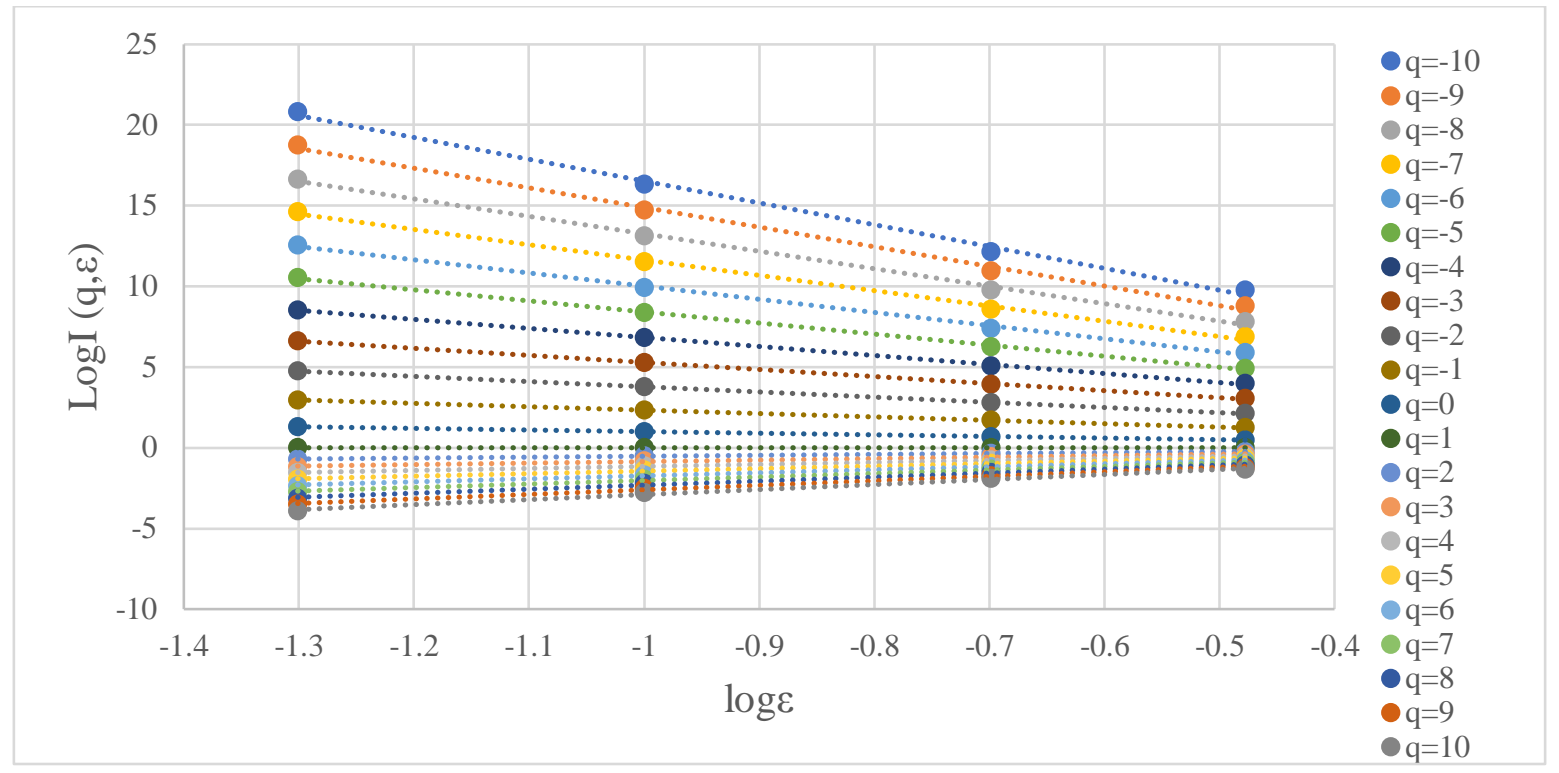

(a) Sample 1 (Upper Bakken)

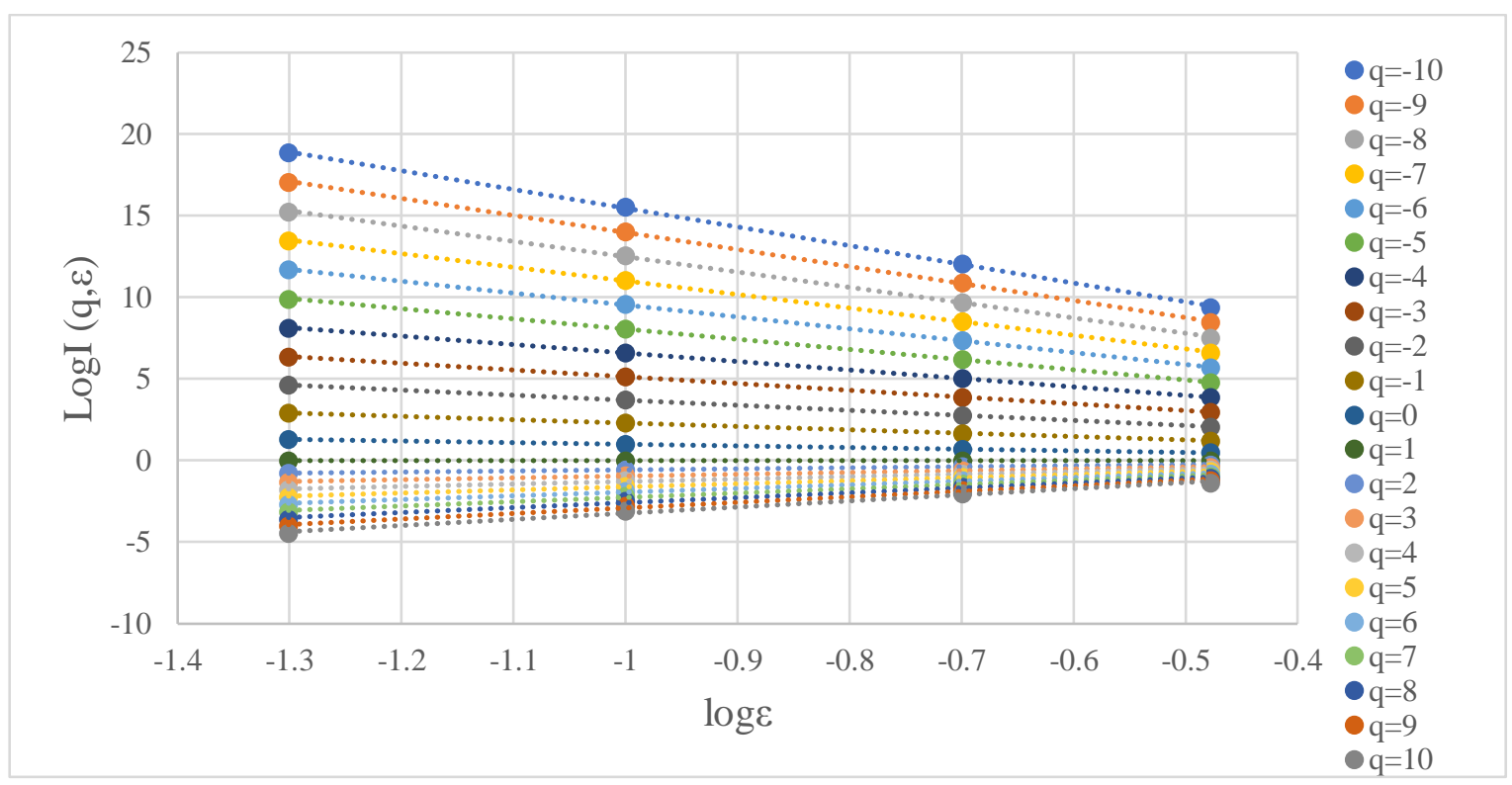

(b) Sample 5 (Middle Bakken) 


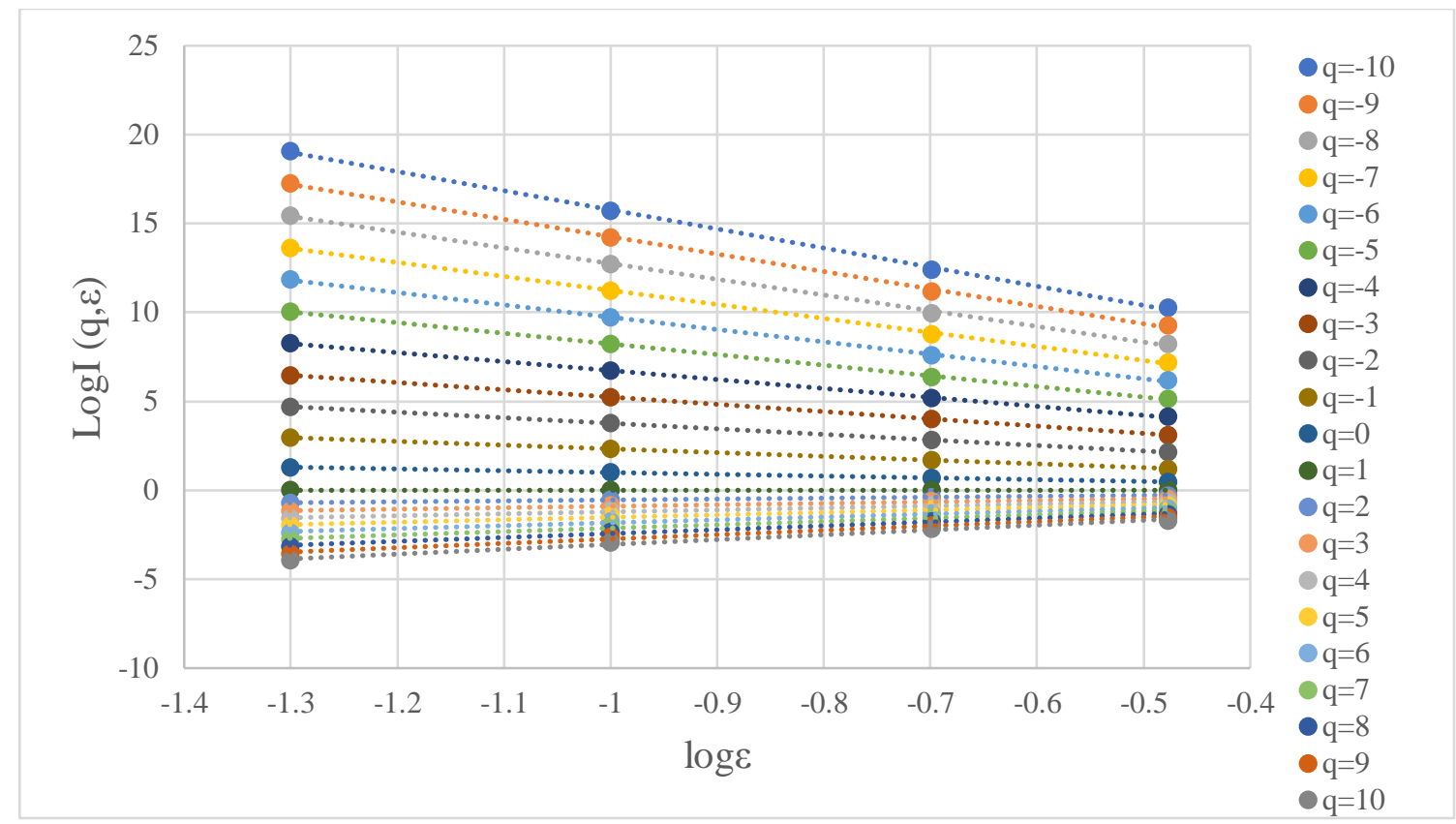

(c) Sample 9 (Lower Bakken)

Fig. 5. Log-log plots of the partition function versus box scale of the representative samples from different members of the Bakken from $\mathrm{N}_{2}$ adsorption isotherms.

The generalized dimensions from the nitrogen adsorption were calculated and are shown in Fig. 6. Considering all of the samples from the Bakken Formation, $D_{q}$ decreases as $q$ increases. Table 3 shows the characteristics of the generalized dimension from our samples derived from nitrogen adsorption. $D_{0}$ that was calculated from the nitrogen adsorption isotherms are similar with the results obtained by other researchers in the soil science field [49-50]. It was realized that the Middle Bakken has a larger $D_{0}-D_{l}$ value (with an average value of 0.2133 ) in comparison to the Upper and Lower Bakken with average $D_{0}$ - $D_{l}$ values of 0.1964 and 0.1582, respectively. This illustrated that the samples from the Middle Bakken have more clustered pore size data while samples from the Lower Bakken has a more uniform pore size distribution. Sample 10 and Sample 6 had the smallest and the largest $D_{0}-D_{l}$ values, respectively, indicating the most and the least uniformity of pore size distributions. This conclusion was also confirmed by the pore size distribution curves of each sample shown in Fig. 7. Fig. 7 shows the pore size distribution from the nitrogen gas adsorption. Comparing pore size distributions of our samples with other major shale formations such as the Eagle Ford or the Barnett, it was found that our samples from the Bakken Formation exhibited much lower pore volumes [56]. $D_{2}$ of the samples from the Upper and the Middle Bakken found very close in values and smaller than the $D_{2}$ of the samples from the Lower Bakken. The Hurst exponent of the samples from the Lower Bakken found to be the largest, demonstrating that the pore connectivity of the Lower Bakken is the best among these three members. The $(1-H)$ value of the samples from the Lower Bakken 
was calculated to be the smallest, meaning that the Lower Bakken samples have the highest autocorrelation degree in a size dependent distribution of porosity.

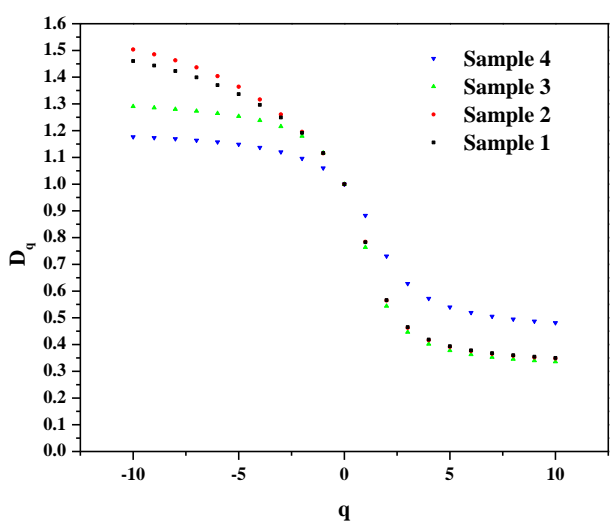

(a) Upper Bakken

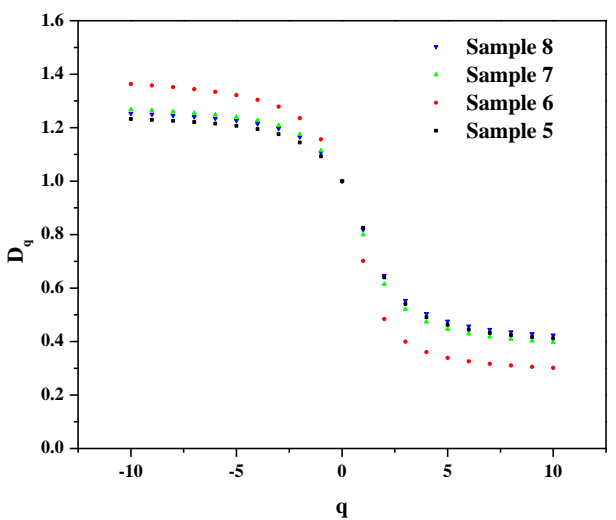

(b) Middle Bakken

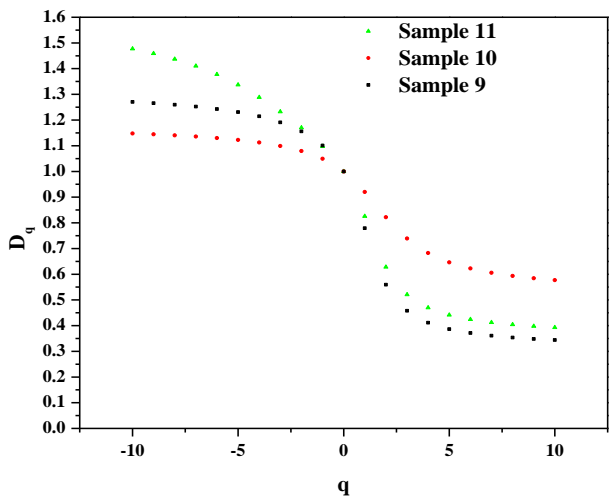

(c) Lower Bakken

Fig. 6. Generalized dimensions of the samples from the $\mathrm{N}_{2}$ adsorption.

Table 3 Characteristics of the generalized dimension from all the samples from nitrogen adsorption

\begin{tabular}{ccccccccc}
\hline & $D_{10+}$ & $D_{10-}$ & $D_{0}$ & $D_{1}$ & $D_{2}$ & $D_{0-} D_{1}$ & $D_{10-}-D_{10+}$ & $H$ \\
\hline Sample 1 & 0.3501 & 1.4604 & 0.9997 & 0.7826 & 0.5661 & 0.2171 & 1.1103 & 0.7831 \\
\hline Sample 2 & 0.3480 & 1.5033 & 0.9997 & 0.7841 & 0.5648 & 0.2156 & 1.1553 & 0.7824 \\
\hline Sample 3 & 0.3359 & 1.2904 & 0.9997 & 0.7638 & 0.5440 & 0.2359 & 0.9545 & 0.7720 \\
\hline Sample 4 & 0.4815 & 1.1767 & 0.9997 & 0.8826 & 0.7307 & 0.1171 & 0.6952 & 0.8654 \\
\hline Sample 5 & 0.4119 & 1.2322 & 0.9997 & 0.8253 & 0.6400 & 0.1744 & 0.8203 & 0.8200 \\
\hline Sample 6 & 0.3015 & 1.3633 & 0.9997 & 0.7018 & 0.4842 & 0.2979 & 1.0618 & 0.7421 \\
\hline
\end{tabular}




\begin{tabular}{ccccccccc} 
Sample 7 & 0.3975 & 1.2675 & 0.9997 & 0.7997 & 0.6147 & 0.2000 & 0.8700 & 0.8074 \\
\hline Sample 8 & 0.4240 & 1.2534 & 0.9997 & 0.8190 & 0.6472 & 0.1807 & 0.8294 & 0.8236 \\
\hline Sample 9 & 0.3438 & 1.2705 & 0.9997 & 0.7790 & 0.5593 & 0.2207 & 0.9267 & 0.7797 \\
\hline Sample 10 & 0.5769 & 1.1476 & 0.9997 & 0.9202 & 0.8220 & 0.0795 & 0.5707 & 0.9110 \\
\hline Sample 11 & 0.3928 & 1.4772 & 0.9997 & 0.8253 & 0.6279 & 0.1744 & 1.0844 & 0.8140 \\
\hline
\end{tabular}

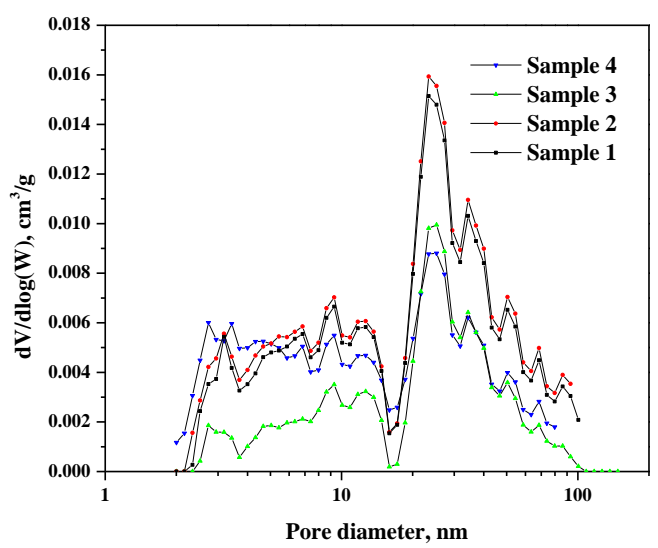

(a) Upper Bakken

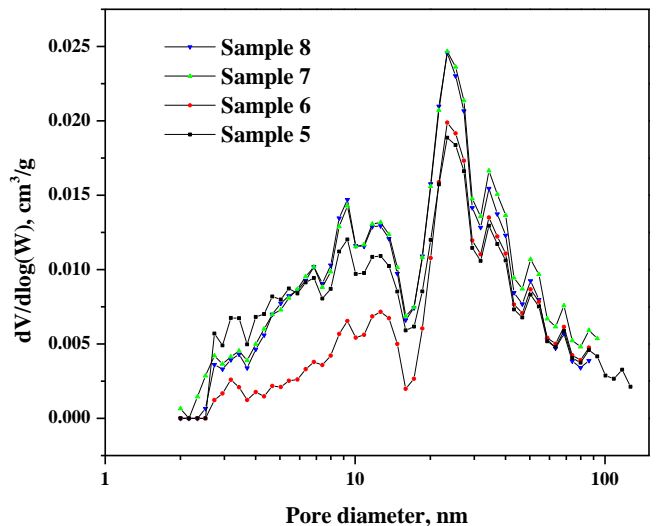

(b) Middle Bakken

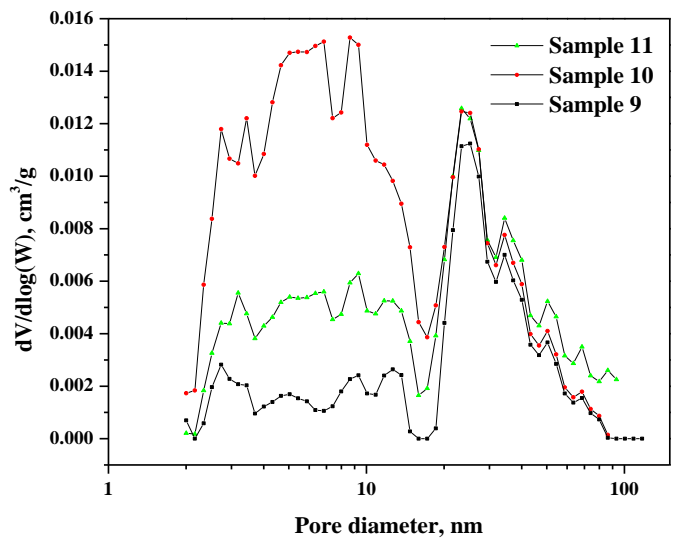

(c) Lower Bakken

Fig. 7. Pore size distributions of the samples from the $\mathrm{N}_{2}$ adsorption.

The difference between $D_{10-}$ and $D_{10+}$, which is shown as $\left(D_{10-} D_{10+}\right)$ of the $D_{q}$ spectrum, can characterize the heterogeneity of the porosity distribution over complete collected pore size distribution data. Nitrogen adsorption was capable to detect pore sizes in a range of 2-200 $\mathrm{nm}$ in our samples. We found that the Upper Bakken has the highest $D_{10-}-D_{10+}$ value with an average of 0.9788 , compared to the Middle and Lower 
Bakken with average values of 0.8954 and 0.8606 , respectively. This is interpreted to mean that the Upper Bakken has the most heterogeneous pore distribution while the Lower Bakken has the least.

The $f(\alpha)$ curve of the samples, plotted in Fig. 8, expresses a convex parabolic shape, indicating that pore size distributions (2-200nm) of our samples exhibit a multifractal behavior. The results in Table 4 indicate that samples from the Middle Bakken have a higher $\alpha_{0}$ value (average of 1.1407) compared to the samples from the Upper and the Lower Bakken with average $\alpha_{0}$ values of 1.1389 and 1.1123 , respectively. This is explained by the fact that the Middle Bakken has a slight higher concentrative degree of pore size distributions, which also confirms the results in Fig. 7 and the Hurst exponent. Regarding $\alpha_{10-} \alpha_{10+}$, the Upper Bakken exhibits the largest value followed by the Lower and then by the Middle Bakken with average values of $1.1253,0.9927$, and 0.9721 , respectively. In terms of the internal difference for multifractal analysis of pore size distributions, the Upper Bakken with the largest $\alpha_{10-}-\alpha_{10+}$ value and the highest degree of internal difference. Consequently, samples from the Upper Bakken are found to be the most heterogeneous ones with respect to pore size distributions while the Middle Bakken is the most homogeneous. The $R_{d}$ of all samples were calculated to be positive, presenting that pore size distributions of these samples are dominated mostly by the areas with lower probability (sparse areas).

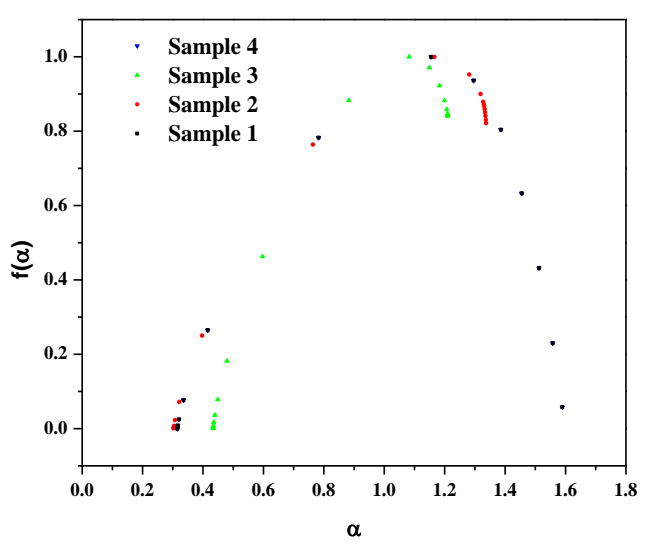

(a) Upper Bakken

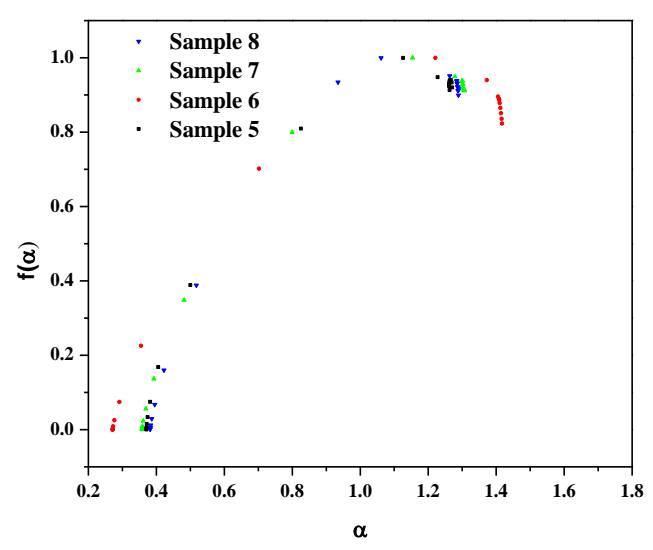

(b) Middle Bakken 


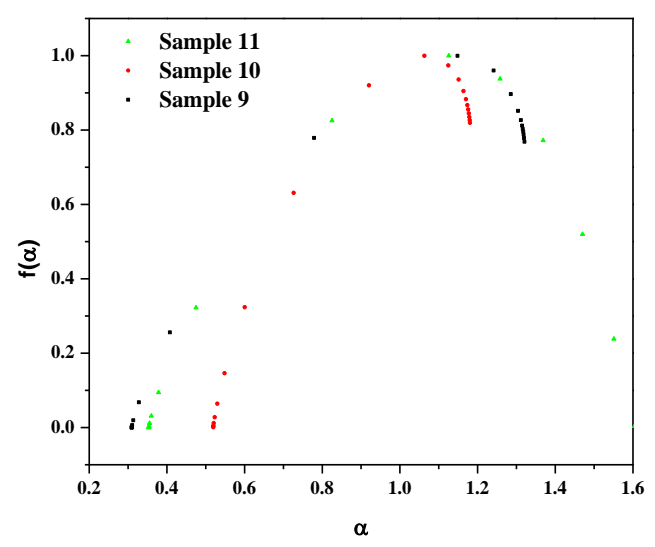

(c) Lower Bakken

Fig. 8. Multifractal singularity spectra, $\mathrm{f}(\alpha)$ for the Bakken samples from $\mathrm{N}_{2}$ adsorption isotherms.

Table 4 Characteristics of the multifractal singularity spectra from $\mathrm{N}_{2}$ adsorption

\begin{tabular}{cccccccc}
\hline & $\alpha_{0}$ & $\alpha_{10+}$ & $\alpha_{10-}$ & $\alpha_{0^{-}} \alpha_{10+}$ & $\alpha_{10-} \alpha_{0}$ & $\alpha_{10-}-\alpha_{10+}$ & $R_{d}$ \\
\hline Sample 1 & 1.1550 & 0.3151 & 1.6321 & 0.8399 & 0.4771 & 1.3170 & 0.3628 \\
\hline Sample 2 & 1.1524 & 0.3132 & 1.6858 & 0.8392 & 0.5334 & 1.3726 & 0.3058 \\
\hline Sample 3 & 1.1660 & 0.3023 & 1.3373 & 0.8637 & 0.1713 & 1.0350 & 0.6924 \\
\hline Sample 4 & 1.0823 & 0.4334 & 1.2099 & 0.6489 & 0.1276 & 0.7765 & 0.5213 \\
\hline Sample 5 & 1.1262 & 0.3707 & 1.2613 & 0.7555 & 0.1351 & 0.8906 & 0.6204 \\
\hline Sample 6 & 1.2211 & 0.2714 & 1.4173 & 0.9497 & 0.1962 & 1.1459 & 0.7535 \\
\hline Sample 7 & 1.1540 & 0.3578 & 1.3029 & 0.7962 & 0.1489 & 0.9451 & 0.6473 \\
\hline Sample 8 & 1.0613 & 0.3817 & 1.2888 & 0.6796 & 0.2275 & 0.9071 & 0.4521 \\
\hline Sample 9 & 1.1482 & 0.3094 & 1.3207 & 0.8388 & 0.1725 & 1.0113 & 0.6663 \\
\hline Sample 10 & 1.0631 & 0.5193 & 1.1804 & 0.5438 & 0.1173 & 0.6611 & 0.4265 \\
\hline Sample 11 & 1.1257 & 0.3535 & 1.6591 & 0.7722 & 0.5334 & 1.3056 & 0.2388 \\
\hline
\end{tabular}

It is well understood that $\mathrm{CO}_{2}$ adsorption can be used to analyze pore structures in the microscale $(<2 \mathrm{~nm})$ while $\mathrm{N}_{2}$ is suitable to detect and characterize the pores in a meso- to macro-scale $(2-200 \mathrm{~nm})$ level [4, 8, $20,58]$. The integration of the two methods can help to better understand pore size information for pores less than $200 \mathrm{~nm}$. In this study, we acquired multifractal analysis results from $\mathrm{CO}_{2}$ adsorption to represent the heterogeneity information of the micropores and then combined that with the results from nitrogen adsorption as the heterogeneity information of meso- and macropores (2-200 nm). Thus, this will provide us with comprehensive heterogeneity information over a wide range of pore sizes. Based on the analysis 
and results that were presented in sections 3.1 and 3.2, it can be concluded that, regarding micropores, the Middle Bakken is the most heterogeneous while considering meso- and macropores, the Upper Bakken is the most heterogeneous in terms of pore size distributions.

Figure 9 shows the comparison results of micropores and meso-macropores of the samples that were analyzed in this study. It can be found that micropores in the Bakken samples are less heterogeneous (Fig. 9a) and show a larger Hurst exponent (Fig. 9b) compared to the meso-macropores. This is a good representation that micropores in the Bakken Formation have a better connectivity and more homogeneity regarding their distribution. Samples with the largest meso-macro pore heterogeneity do not have the highest micropore heterogeneity. No clear relationship can be found between the micro-pore heterogeneity and meso-macro-pore heterogeneity (Fig. 9c), indicating that the micropore heterogeneity and the mesomacro pore heterogeneity needs to be analyzed separately.

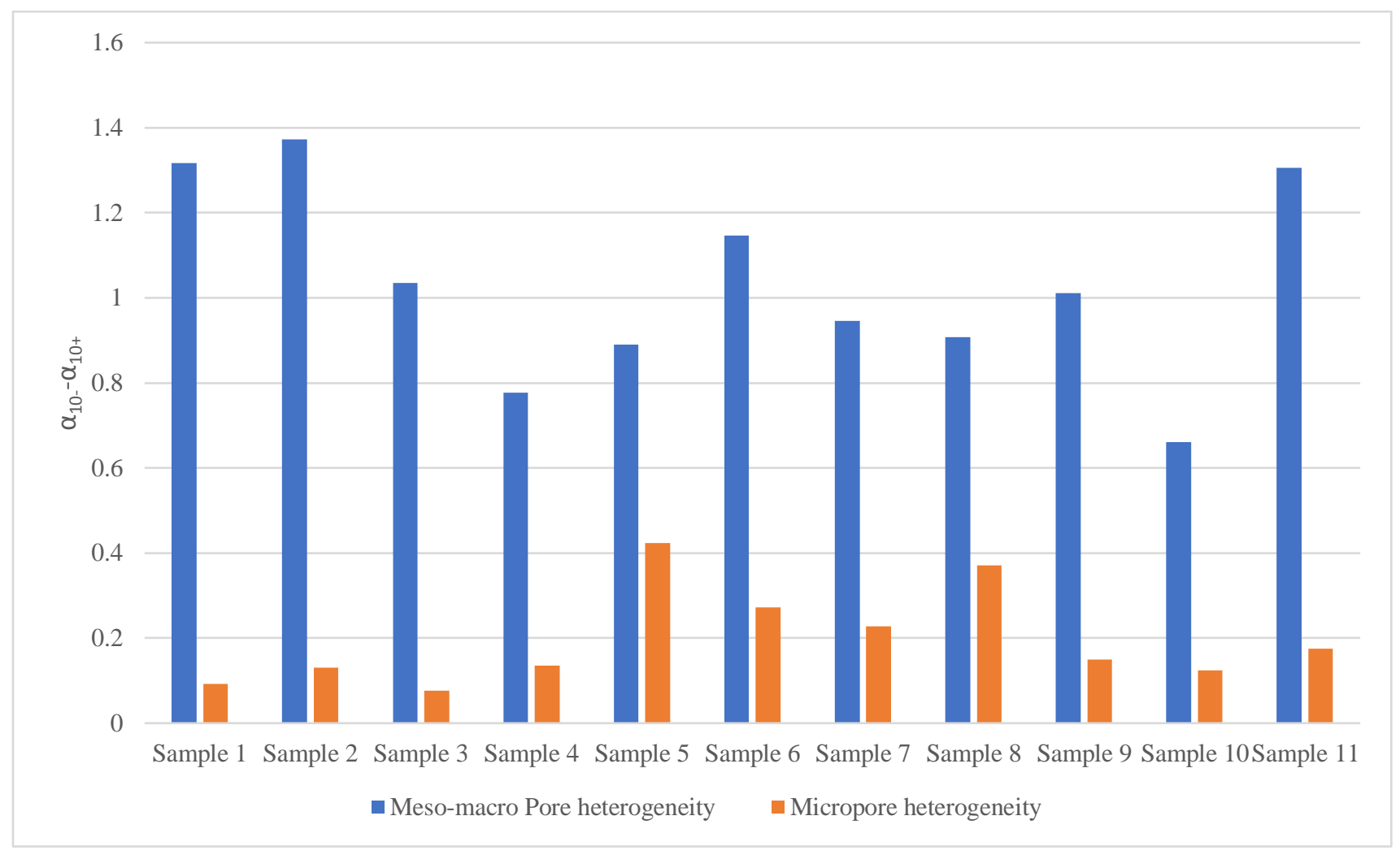

(a) Heterogeneity 


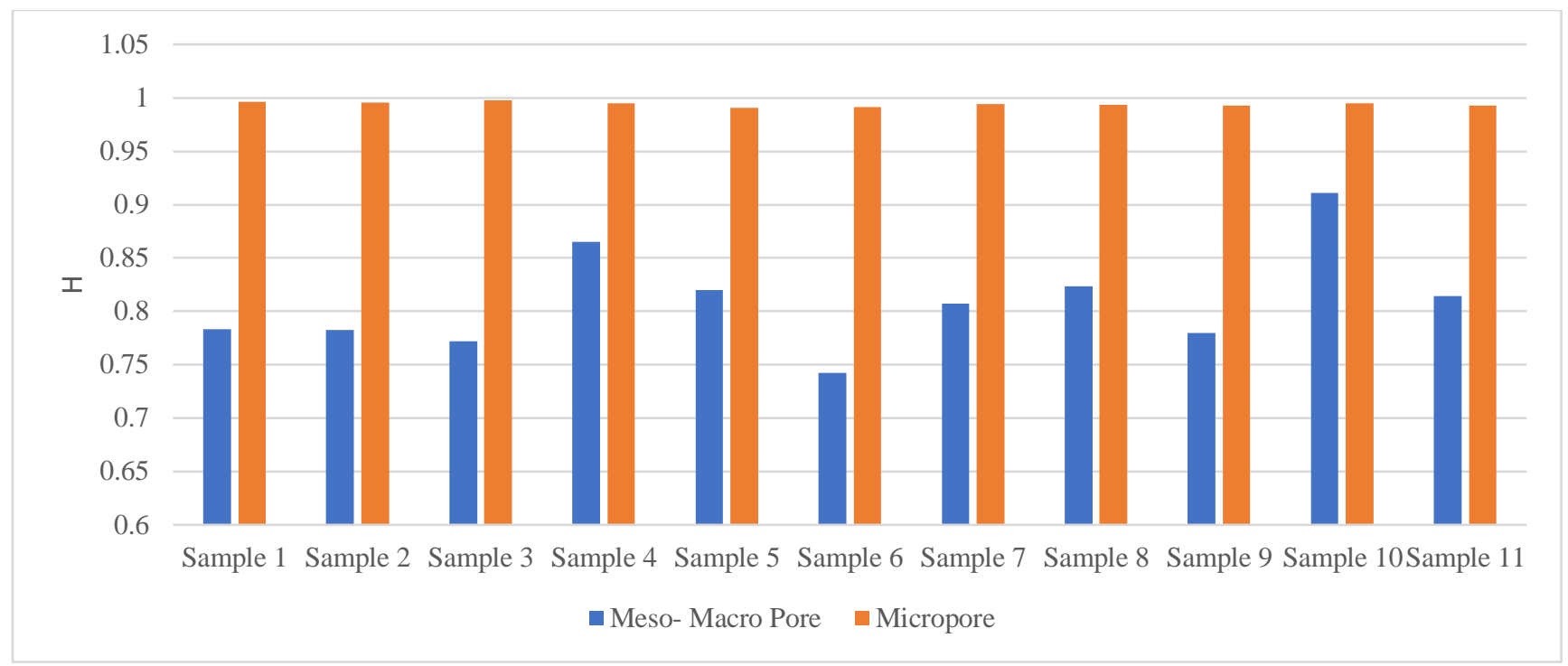

(b) Hurst exponent

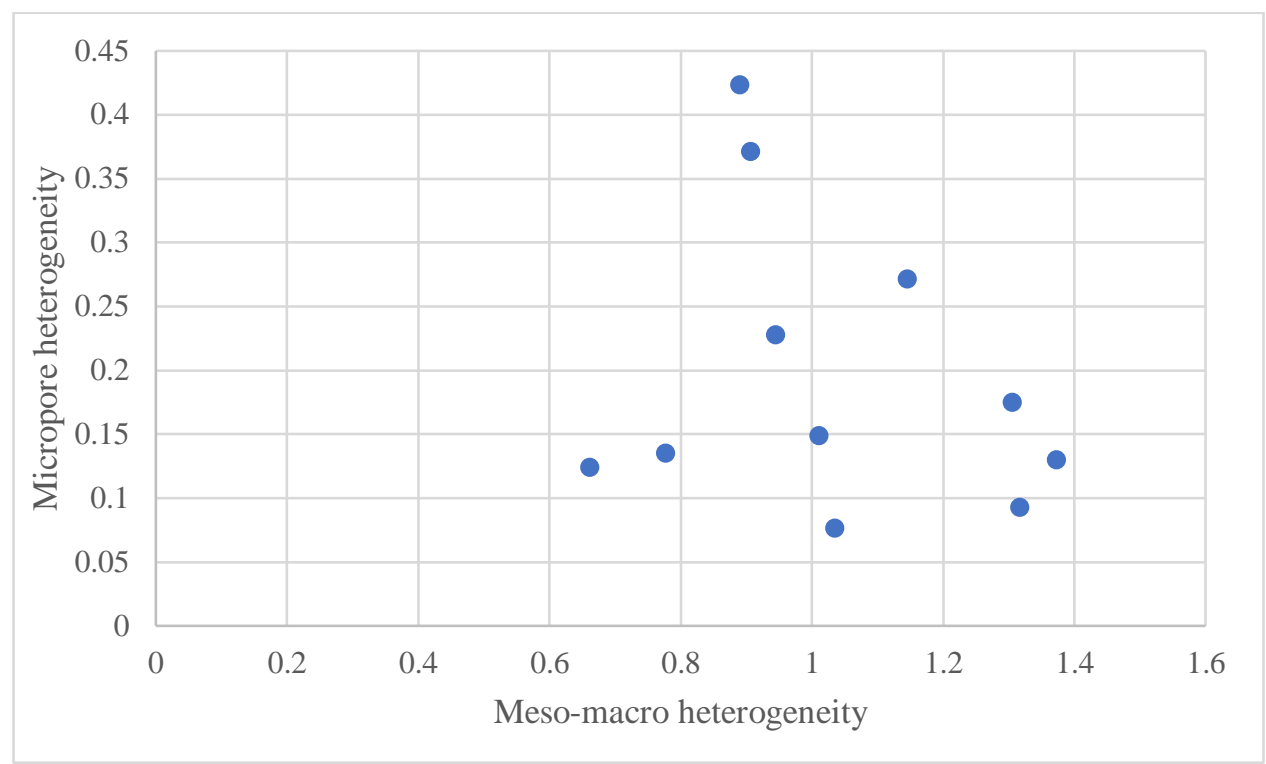

(c) Correlation between the micropore heterogeneity and meso-macropore heterogeneity

Fig. 9. Comparison of the pore structure information of the samples.

\subsection{Potential factors affecting heterogeneity of pore structures}

In order to analyze the factors that could potentially affect the heterogeneity of pore structures, it was decided to investigate these factors for micro- and meso-macro size range of pores, separately.

\subsubsection{The impact of pore volume}

We plotted pore volume on the $\mathrm{x}$-axis versus the heterogeneity index $\left(\alpha_{10^{-}} \alpha_{10+}\right)$ on the $\mathrm{y}$-axis to find whether pore volume has any effect on pore heterogeneity. Based on the results in Fig. 10, we were not able to 
establish any strong correlation between pore volume and heterogeneity. Therefore, we may conclude that pore volume or porosity as a quantity is not a valid constraint on the heterogeneity of the meso-macro pores, which agrees with our previous study that related heterogeneity index and porosity using SEM images [41]. For micropores, we can deduce that as pore volume increases, pore heterogeneity appears to have a decreasing tendency.

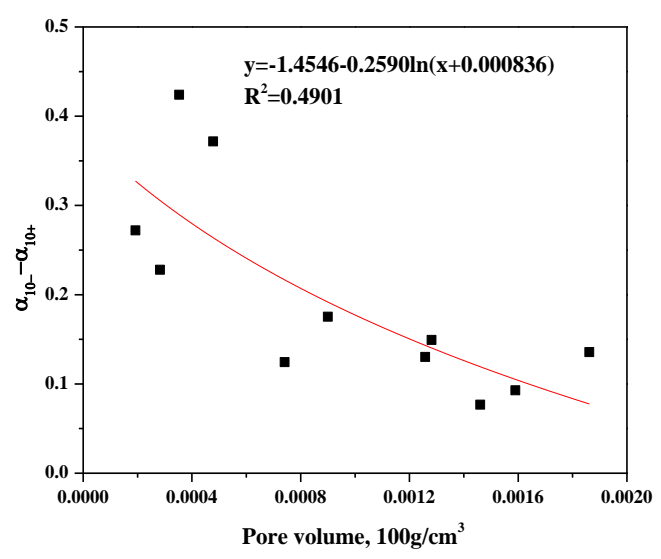

(a) micropores $(<2 \mathrm{~nm})$

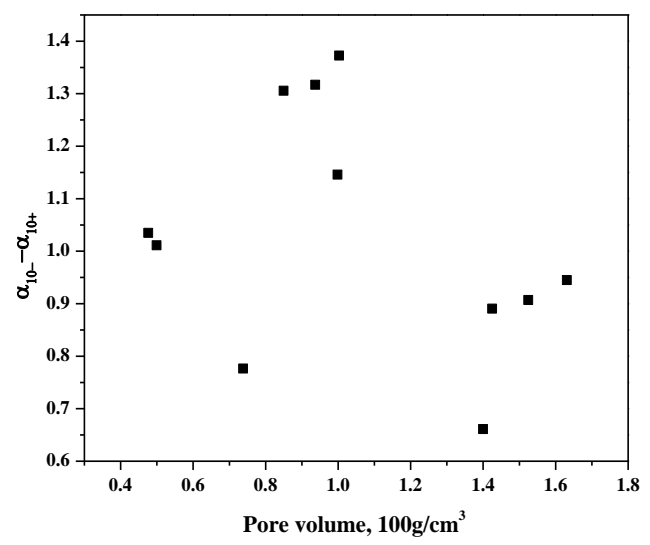

(b) meso-macro pores $(2-200 \mathrm{~nm})$

Fig. 10. Correlations between the pore volume and the heterogeneity of the pores.

\subsubsection{The impact of the rock compositions}

Among our samples, the ones chosen from the Upper and the Lower Bakken are organic-rich while the Middle Bakken samples are composed of mostly mixed carbonates and fine-grained clastics. Considering this difference in constituent components, we categorized the Upper and Lower Bakken under group I and the Middle Bakken as group II in order to study them separately. To illustrate if mineralogy can control pore heterogeneity, partial least-squares regression (PLS), which is a measure of how one parameter can impact the other one, was employed [4]. To apply PLS to our data, rock compositions were taken as the independent variable while the pore heterogeneity index $\left(\alpha_{10-}-\alpha_{10+}\right)$ and the Hurst parameter as the dependent components. Table 5 and Table 6 summarize rock compositions of the samples in group I and group II, respectively. In addition, Table 7 and Table 8 show the PLS results from the samples in group I and group II, respectively. Table 5 and Table 6 show that quartz is the dominant mineral in these samples. The TOC (total organic carbon) of the samples from the Upper and the Lower Bakken was recorded more than $10 \%$ wt., reflecting the organic-rich nature of the studied samples with the kerogen been mostly type II marine [57]. In addition, the main clay mineral in these samples was found to be illite [57]. 
Table 7 shows that for micropores within the Upper and Lower Bakken, quartz and clay will slightly reduce the pore connectivity and increase the pore heterogeneity whereas pyrite and feldspar increase pore connectivity and reduce pore heterogeneity. For meso-macro pores of these samples, quartz and clay were found to increase pore connectivity and lower pore heterogeneity while pyrite and feldspar have an opposite effect. Among all constituent components, organic matter was found to impact both pore connectivity and heterogeneity the most, and for all ranges of pore sizes. We realized that organic matter could increase the micropore connectivity and decrease the micropore heterogeneity. This finding can also be an indication of the existence of micropores associated with the organic matter.

Table 8 data, which summarize the impact of rock composition on pore heterogeneity of the samples from the Middle Bakken, exhibit a slight difference in values than the previous group (upper and lower members). The results demonstrate that quartz and pyrite have a negative effect on pore connectivity both in micro and meso-macro scale while feldspar, clay, and calcite can increase pore network connectivity in micro to macro scale. Dolomite enhances micropore connectivity while it deteriorates the connectivity of meso-macro pores. Regarding pore heterogeneity, clay, feldspar, and calcite reduce the heterogeneity of both micropores and meso-macro pores whereas, quartz, and pyrite increase micro to macro pore heterogeneity.

Table 5 Rock compositions of the samples from the Upper and Lower Bakken ${ }^{4}$

\begin{tabular}{llcccccc}
\hline & & Quartz, \% & Pyrite, \% & Feldspar, \% & Clay, \% & Dolomite, \% & TOC, \% \\
\hline \multirow{3}{*}{$\begin{array}{l}\text { Upper } \\
\text { Bakken }\end{array}$} & Sample 1 & 48.44 & 20.06 & 7.63 & 9.60 & 0.00 & 14.27 \\
\cline { 2 - 8 } & Sample 2 & 13.94 & 2.31 & 45.36 & 19.79 & 0.00 & 17.53 \\
\cline { 2 - 8 } & Sample 3 & 40.26 & 2.32 & 3.36 & 39.57 & 0.00 & 13.97 \\
\cline { 2 - 8 } & Sample 4 & 41.85 & 3.98 & 13.22 & 22.01 & 6.09 & 13.00 \\
\hline \multirow{2}{*}{$\begin{array}{l}\text { Lower } \\
\text { Bakken }\end{array}$} & Sample 9 & 48.16 & 4.90 & 2.08 & 24.91 & 0.00 & 16.96 \\
\cline { 2 - 8 } & Sample 10 & 44.36 & 2.69 & 2.78 & 33.22 & 0.00 & 10.21 \\
\cline { 2 - 8 } & Sample 11 & 39.36 & 4.65 & 5.90 & 29.52 & 0.00 & 10.55 \\
\hline
\end{tabular}

Table 6 Rock compositions of the samples from the Middle Bakken ${ }^{4}$

\begin{tabular}{ccccccc}
\hline & Quartz, \% & Pyrite, \% & Feldspar, \% & Clay, \% & Dolomite, \% & Calcite, \% \\
\hline Sample 5 & 37.54 & 0.10 & 11.10 & 14.50 & 11.00 & 25.70 \\
\hline Sample 6 & 38.25 & 2.29 & 13.20 & 13.60 & 25.00 & 7.60 \\
\hline Sample 7 & 24.74 & 1.09 & 9.50 & 42.22 & 12.40 & 9.80 \\
\hline Sample 8 & 16.85 & 0.67 & 6.39 & 62.94 & 5.24 & 7.50 \\
\hline
\end{tabular}

Table 7 PLS results of the Upper and the Lower Bakken 


\begin{tabular}{ccccc}
\hline Variable & Micropore H & Micropore Index & Meso-macro Pore H & Meso-macro Pore Index \\
\hline Intercept & 0.994668 & 0.130531 & 0.846872 & 0.874269 \\
\hline Quartz & -0.000009 & 0.000086 & 0.000651 & -0.004013 \\
\hline Pyrite & 0.000019 & -0.000176 & -0.001332 & 0.008209 \\
\hline feldspar & 0.000007 & -0.000069 & -0.000520 & 0.003203 \\
\hline clay & -0.000010 & 0.000096 & 0.000721 & -0.004444 \\
\hline Organic matter & 0.000064 & -0.000595 & -0.004487 & 0.027658 \\
\hline
\end{tabular}

Table 8 PLS results of the Middle Bakken

\begin{tabular}{ccccc}
\hline Variable & Micropore H & Micropore Index & Meso-macro Pore H & Meso-macro Pore Index \\
\hline Intercept & 0.983958 & 0.957752 & 0.796001 & 1.018137 \\
\hline Quartz & -0.000711 & 0.038123 & -0.003635 & 0.012458 \\
\hline Pyrite & -0.001817 & 0.085394 & -0.024920 & 0.084494 \\
\hline feldspar & 0.002570 & -0.152274 & 0.010655 & -0.039664 \\
\hline clay & 0.000073 & -0.003296 & 0.000416 & -0.001281 \\
\hline dolomite & 0.000146 & -0.010848 & -0.000629 & 0.001610 \\
\hline Calcite & 0.000077 & -0.004418 & 0.001765 & -0.006293 \\
\hline
\end{tabular}

\subsubsection{The impact of maturity}

Besides total organic content, which could affect the heterogeneity of the pore structures, the maturity of source rocks can be another parameter that could significantly influence pore structures [57-58]. Thus, it is important to investigate if the samples in group I are affected by different maturity levels with respect to their pore structures and corresponding heterogeneity. Thermal maturity of the organic matter in source rocks can be evaluated by vitrinite reflectance or equivalent reflectance of other macerals, such as solid bitumen in the absence of vitrinite [59]. To carry out this analysis, the maturity of the samples was plotted on the $\mathrm{x}$-axis versus $\mathrm{H}$ and $\alpha_{10} \alpha_{10+}$ in two separate plots on the y-axis. Hence, the effect of maturity on pore connectivity and pore heterogeneity on the pores at different size scales can be concluded from Fig. 11. As a result of the plots and for the samples that were analyzed for this study, we were not able to establish any strong correlation between maturity and pore connectivity (Fig. 11a, c) and heterogeneity (Fig. $11 \mathrm{~b}, \mathrm{~d})$.

In this study, we attempted to relate different parameters that represent the multifractal behavior of PSD curves to pore connectivity of the samples. Additionally, we investigated the impact of various components on pore network and relevant heterogeneities. We also made conclusions on how major constituent components may affect heterogeneity and what each multifractal parameter may disclose about pore network connectivity. Considering the importance that the existence of different pore sizes and their 
connectivity have on permeability, especially in unconventional reservoirs, and in order to validate our conclusions, the use of microcomputed tomography ( $\mu \mathrm{CT}$ ) imaging is necessary. This would be a valuable tool and its use would be highly recommended in future studies in order to examine the connectivity of pores in similar samples.

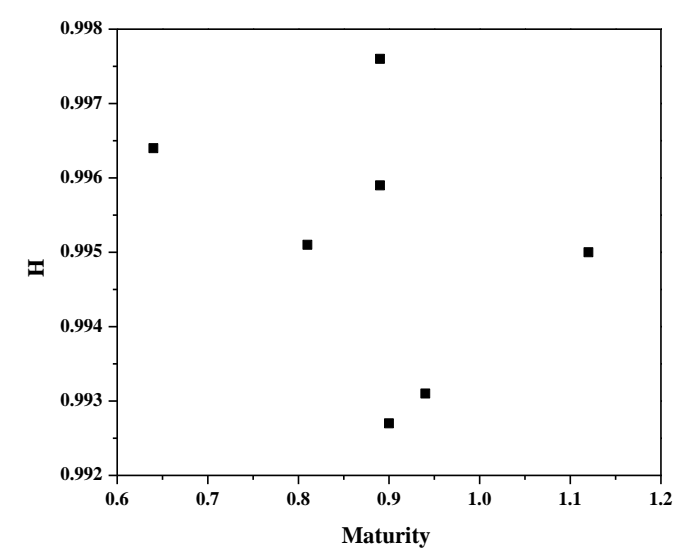

(a) micropore $\mathrm{H}$

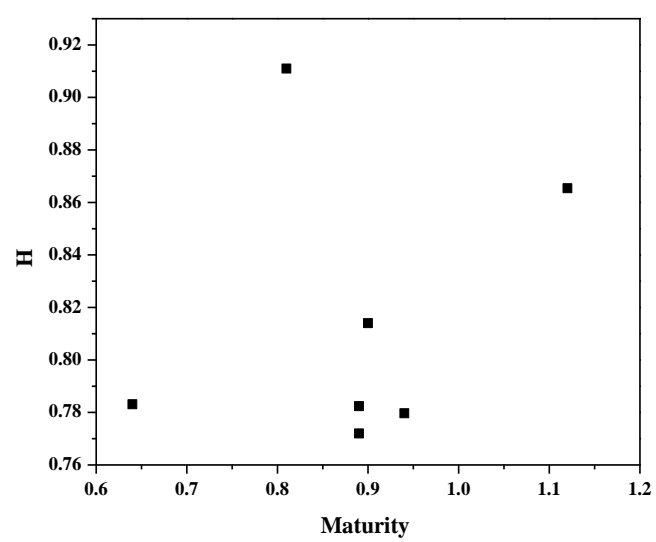

(c) meso-macro pore $\mathrm{H}$

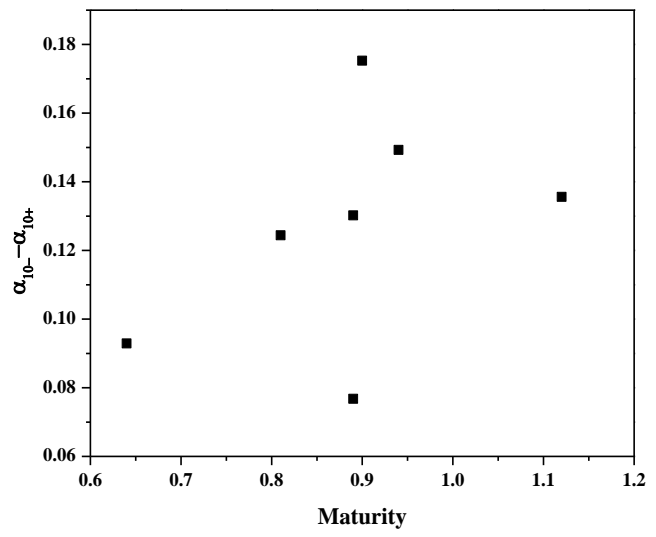

(b) micropore heterogeneity

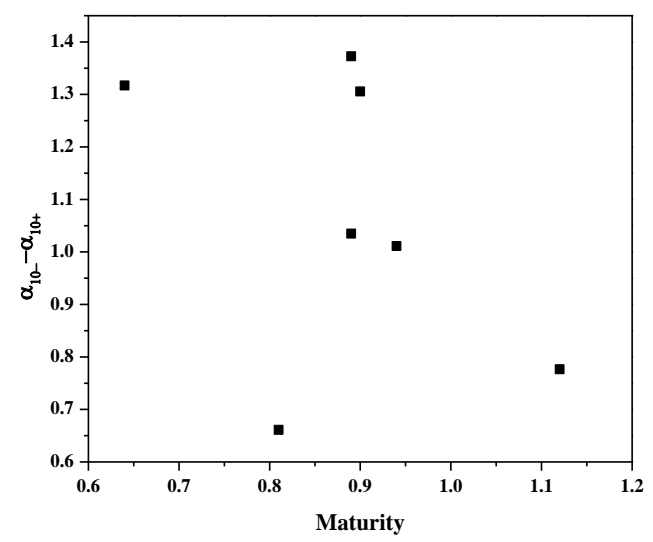

(d) Meso-macro pore heterogeneity

Fig. 11. Impact of the maturity on the pore connectivity and heterogeneity.

\section{Conclusions}

In the presented research, we collected several samples from the Bakken Formation and applied multifractal analysis method to characterize the heterogeneity of pore structures on a wide range of pore sizes. In order 
to do so, $\mathrm{CO}_{2}$ and $\mathrm{N}_{2}$ adsorption were employed to detect micro and meso-macro pores, respectively. Based on this study, the following conclusions were made:

1. Both $\mathrm{CO}_{2}$ and $\mathrm{N}_{2}$ adsorption isotherms revealed the multifractal nature of different pore sizes that were detected in our samples.

2. Middle Bakken was found to have the most bundled (concentration) pore size distribution in both micropore $(<2 \mathrm{~nm})$ and meso-macropore range $(2-200 \mathrm{~nm})$. Additionally, the samples from the Middle Bakken showed the worst micropore connectivity.

3. Samples from the Middle Bakken exhibited the most heterogeneous characteristic in micropores while the Upper Bakken the most heterogeneous nature of meso and macro pores.

4. We were not able to establish a clear correlation between pore volume and heterogeneity, also maturity and heterogeneity and maturity and pore connectivity.

5. For samples taken from the Upper and the Lower Bakken, quartz and clay were found to reduce micropore connectivity and increase micropore heterogeneity while enhancing meso-macro pore connectivity and reducing meso-macro pore heterogeneity. Considering major constituent components of the samples, organic matter showed to have the most influence on pore heterogeneity and connectivity.

6. For samples taken from the Middle Bakken, quartz and pyrite were found to decrease pore connectivity and increase pore heterogeneity of all range of pore sizes whereas clay minerals were found to have an opposite effect on pore connectivity and pore heterogeneity.

\section{Acknowledgement}

The authors appreciate the support from China Scholarship Council (201406450029) and the reviewers for their constructive comments, which improved the quality of the manuscript.

\section{References}

[1] Yin M, Huang H, and Ma J. Pore size constrains on hydrocarbon biodegradation in shales from the Second White Speckled Shale Formation of the Western Canada Sedimentary Basin. Fuel. 2016; 185: 639-648.

[2] Wei Z, Wang Y, Wang G, et al. Pore characterization of organic-rich Late Permian Da-long Formation shale in the Sichuan Basin, southwestern China. Fuel. 2018; 211: 507-516.

[3] Zou J, Rezaee R, and Liu K. The effect of temperature on methane adsorption in shale gas reservoirs. Energy \& Fuels. 2017; 31: 12081-12092.

[4] Liu K, Ostadhassan M, Zhou J, et al. Nanoscale pore structure characterization of the Bakken shale in the USA. Fuel. 2017; 209: 567-578.

[5] Bowker KA. Barnett Shale gas production, Fort Worth Basin: issues and discussion. AAPG Bull. 2007; 91(4): 523-533.

[6] Wang FP, Reed RM. Pore networks and fluid flow in gas shales. SPE annual technical conference and exhibition. Society of Petrole $\mu \mathrm{m}$ Engineers. 2009.

[7] Kirchofer A, Firouzi M, Psarras P, \& Wilcox J. Modeling $\mathrm{CO}_{2}$ Transport and Sorption in Carbon Slit Pores. J. Phys. Chem. C. 2017;121(38): 21018-21028. 
[8] Aljama $\mathrm{H}$, \& Wilcox J. Microscopic diffusion of $\mathrm{CO}_{2}$ in clay nanopores. Chem.Phys. Lett. 2017; 677,162-166.

[9] Gao ZY, and Hu QH. Estimating permeability using median pore-throat radius obtained from mercury intrusion porosimetry. J. Geophys. Eng. 2013; 10(2) : 025014.

[10] Huang XF, and Zhao YP. Characterization of pore structure, gas adsorption, and spontaneous imbibition in shale gas reservoirs. J. Petrol. Sci. Eng.. 2017; 159:197-204.

[11] Clarkson CR, Solano N, Bustin RM, et al. Pore structure characterization of North American shale gas reservoirs using USANS/SANS, gas adsorption, and mercury intrusion. Fuel. 2013; 103: 606-616.

[12] Zhao PQ, et al . Investigation on the pore structure and multifractal characteristics of tight oil reservoirs using NMR measurements: Permian Lucaogou Formation in Jimusaer Sag, Junggar Basin. Mar. Pet. Geol. 2017; 86: 1067-1081.

[13] Liu K, Ostadhassan M.. Quantification of the microstructures of Bakken shale reservoirs using multifractal and lacunarity analysis. J. Nat. Gas Sci. Eng. 2017; 39, 62-71.

[14] Loucks RG, Reed RM, Ruppel SC, et al. Morphology, Genesis, and Distribution of Nanometer-Scale Pores in Siliceous Mudstones of the Mississippian Barnett Shale. J. Sediment Res. 2009; 79(12): 848-861.

[15] Klaver J, Desbois G, Urai JL, Littke R. BIB-SEM study of the pore space morphology in early mature Posidonia Shale from the Hils area, Germany. Int. J. Coal Geol. 2012; 103(1): 12-25.

[16] Javadpour F. Nanopores and Apparent Permeability of GasFlow in Mudrocks (Shales and Siltstone). J. Can. Petro. Technol. 2009; 48 (8): 18-21.

[17] Liu K, Ostadhassan M, \& Bubach B. Pore Structure Analysis by Using Atomic Force Microscopy. URTEC 2448210. 2016.

[18] Li ZT, Liu DM, Cai YD, et al. Multi-scale quantitative characterization of 3-D pore-fracture networks in bit $\mu$ minous and anthracite coals using FIB-SEM tomography and X-ray mu-CT. Fuel. 2017; 209 : 43-53.

[19] Su Y, Zha M, Ding XJ, et al. Pore type and pore size distribution of tight reservoirs in the Permian Lucaogou Formation of the Jimsar Sag, Junggar Basin, NW China. Mar. Pet. Geol. 2018; 89:761774.

[20] Bernard S, Horsfield B, Schulz HM. Geochemical evolution of organic-rich shales with increasing maturity: A STXM and TEM study of the Posidonia Shale (Lower Toarcian, northern Germany). Mar. Pet. Geol. 2012; 31(1): 70-89.

[21] Giesch H. MercuryPorosimetry:AGeneral(Practical)Overview. Part. Part. Syst. Charact. 2006; 23: 919.

[22] Anovitz LM, Cole DR. Characterization and Analysis of Porosity and Pore Structures. Rev. Mineral. Geochem. 2015; 80(1): 61-164.

[23] Li W, Liu HF, and Song XX. Multifractal analysis of $\mathrm{Hg}$ pore size distributions of tectonically deformed coals. Int. J. Coal Geol. 2015; 144: 138-152.

[24] Tang H, et al. Impact factors of fractal analysis of porous structure. Sci. China Technol. Sc. 2010; 53(2): 348-351.

[25] Wang HM, Liu Y, Song Y, et al. Fractal analysis and its impact factors on pore structure of artificial cores based on the images obtained using magnetic resonance imaging. J. Appl. Geophys. 2012; 86: 70-81.

[26] Mandelbrot BB. 1977.Fractals: Form, chance, and dimension, W. H. Freeman and Co., New York.

[27] Lopes R, and Betrouni N. Fractal and multifractal analysis: a review. Med. Image Anal. 2009; 13: 634649.

[28] Russel DA, Hanson J, Ott E. Dimension of strange attractors. Phys. Rev. Lett. 1980; 45 (14), $1175-$ 1178.

[29] Chaudhuri B, Sarkar N. Texture Segmentation Using Fractal Dimension. IEEE T. Pattern Anal. 1995; 17 (1): 72-77.

[30] Pentland A. Fractal-based description of natural scenes. IEEE T. Pattern Anal. 1984; 6 (6): 661-674. 
[31] Shelberg M, Lam N, Moellering H. Measuring the fractal dimension of surfaces. Proceedings of the Sixth International Symposium on Computer-Assisted Cartography Auto-Carto. 1983; 6: 319-328.

[32] Peleg S, Naor J, Hartley R, Avnir D. Multiple resolution texture analysis and classification. IEEE T. Pattern Anal. 1984; 6 (6): 661-674.

[33] Clarke K. Computation of the fractal dimension of topographic surfaces using the triangular prism surface area method. Comput. Geosci. 1986; 12 (5):713-722.

[34] Martínez FS, Martin MA, Caniego FJ, et al. Multifractal analysis of discretized X-ray CT images for the characterization of soil macropore structures. Geoderma. 2010; 156: 32-42.

[35] Gould DJ, Vadakkan TJ. Multifractal and Lacunarity analysis of microvascular morphology and remodeling. Microcirculation. 2011; 18(2): 136-151.

[36] Li YH, Gao QL, and Victor R. Compressibility and fractal dimension of fine coal particles in relation to pore structure characterization using mercury porosimetry. Particle \& particle systems characterization. $1999 ; 16: 25-31$.

[37] Muller J, Huseby KO, Saucier A. Influence of multifractal scaling of pore geometry on permeabilities of sedimentary rocks. Chaos, Solitons \& Fractals. 1995; 5(8):1485-1492.

[38] Muller J. Characterization of pore space in chalk by multifractal analysis. J. Hydrol.1996; 187: 215 222.

[39] Xie S, Cheng Q, Ling Q, et al. Fractal and multifractal analysis of carbonate pore scale digital images of petrole $\mu \mathrm{m}$ reservoirs. Mar. Pet. Geol. 2010; 27(2): 476-485.

[40] Pitman JK, Price LC, LeFever JA. Diagenesis and fracture development in the Bakken Formation, Williston Basin; implications for reservoir quality in the middle member. 2001.

_[41] Liu K, and Ostadhassan, M. Quantification of the microstructures of Bakken shale reservoirs using multi fractal and lacunarity analysis. J. Nat. Gas Sei. Eng. 2017; 39: 6271.

[4241] Chen J, Xiao X. Evolution of nanoporosity in organic-rich shales during thermal maturation. Fuel. 2014; 129: 173-181.

[4342] Behar F, Bea pmont V, De B, Penteado HL. Rock-Eval 6 technology: performances and developments. Oil Gas Sci. Technol. 2001; 56: 111-134.

[4443] Do DD, Do HD. Pore characterization of carbonaceous materials by DFT and GCMC simulations: a review. Adsorpt. Sci. Technol. 2003; 21(5): 389-423.

[4544] Amankwah KAG, and Schwarz JA. A modified approach for estimating pseudo-vapor pressures in the application of the Dubinin-Astakhov equation. Carbon. 1995; 33:1313-1319.

[4645] Fan L, and Ziegler T. Nonlocal density functional theory as a practical tool in calculations on transition states and activation energies. Applications to elementary reaction steps in organic chemistry. J. Am. Chem. Soc. 1992; 114: 10890-10897.

[4746] Monson PA. Understanding adsorption/desorption hysteresis for fluids in mesoporous materials using simple molecular models and classical density functional theory. Micropor Mesopor Mat. 2012;160: 47-66.

[4847] Thommes M, Kaneko K, Neimark AV, et al. Physisorption of gases, with special reference to the evaluation of surface area and pore size distribution (IUPAC Technical Report). Pure Appl. Chem. 2015; 87(9-10): 1051-1069.

[4948] Ferreiro JP, Wilson M, and Vázquez EV. Multifractal description of nitrogen adsorption isotherms. Vadose Zone J. 2009; 8: 209-219.

[5059] Ferreiro JP, Miranda JGV, and Vázquez EV. Multifractal analysis of soil porosity based on mercury injection and nitrogen adsorption. Vadose Zone J. 2010; 9: 325-335.

[5150] Feder J. Fractals. Plenum Press, New York. 1988.

[5251] Halsey TC, Hensen MH, Kadanoff LP, et al. Fractal measures and their singularities: the characterization of strange sets. Phys. R. A. 1986; 33(2): 1141-1151.

[5352] Chhabra A, and Jensen RV. Direct Determination of the $f(\alpha)$ singularity spectr $\mu$ m. Phys. Rev. Lett. 1989; 62: 1327. 
[5453] Song Y, Jiang B, Shao P, Wu J. Matrix compression and multifractal characterization for tectonically deformed coals by Hg porosimetry. Fuel. 2018; 211: 661-675.

[5554] Psarras P, Holmes R, Vishal V, \& Wilcox J. Methane and $\mathrm{CO}_{2}$ adsorption capacities of kerogen in the Eagle Ford shale from molecular simulation. Accounts Chem. Res. 2017; 50(8): 1818-1828.

[5655] Holmes R, Rupp EC, Vishal V, \& Wilcox J. Selection of shale preparation protocol and outgas procedures for applications in low-pressure analysis. Energy \& Fuels. 2017;31(9):9043-9051.

[5756] Liu K, Ostadhassan M, Gentzis $\mathrm{T}$ et al. Characterization of geochemical properties and microstructures of the Bakken Shale in North Dakota. Int. J. Coal Geol. 2017. Accept, in press.

[5857] Löhr SC, Baruch ET, Hall PA. Is organic pore development in gas shales influenced by the primary porosity and structure of thermally immature organic matter? Org. Geochem. 2015; 87: 119-132.

[5958] Kuila U, McCarty DK, Derkowski A, Fischer TB, TopórT, \& Prasad M. Nano-scale texture and porosity of organic matter and clay minerals in organic-rich mudrocks. Fuel. 2014; 135:359-373.

[60] Khatibi S, Ostadhassan M, Tuschel D., et al. Raman spectroscopy to study thermal maturity and elastic modulus of kerogen. Int. J. Coal Geol.2018; 185:103-118. 